\title{
Probing Heterogeneous Charge Distributions at the
}

\section{$\alpha-\mathrm{Al}_{2} \mathrm{O}_{3}(0001) / \mathrm{H}_{2} \mathrm{O}$ Interface}

Stefan M. Piontek ${ }^{1}$, Mark DelloStritto $^{3}$, Bijoya Mandal ${ }^{1}$, Tim Marshall ${ }^{1}$, Michael L. Klein ${ }^{2-3}$, and Eric Borguet ${ }^{* 1-2}$

1 Department of Chemistry

2 Center for Complex Materials from First Principles,

3 Institute for Computational Molecular Science

Temple University, Philadelphia, Pennsylvania 19122, United States

AUTHOR INFORMATION

Corresponding Author

eborguet@temple.edu

KEYWORDS vibrational sum frequency generation, alumina, and potassium thiocyanate

\section{Supporting Information}

1. Additional Sample Preparation Details

2. Additional Computational Details

3. Optical Setup

4. VSFG Data Normalization

5. VSFG Spectra of $\mathrm{H}_{2} \mathrm{O}$ in the $\mathrm{CN}$ Stretching Region

6. Comparison of $1 \mathrm{M} \mathrm{KSCN}$ and $\mathrm{KCl}$ solutions vSFG Spectra in the CN Stretching Region 
7. Individual vSFG Spectra of $\mathrm{KSCN}$ at the $\alpha-\mathrm{Al}_{2} \mathrm{O}_{3}(0001) / \mathrm{H}_{2} \mathrm{O}$ Interface

8. Simulation of One and Two Lorentzian Oscillators in the CN Stretching Region

9. Total Fits and Extracted Fit Parameters for Steady State KSCN vSFG Spectra

10. Langmuir Adsorption Isotherms of $\mathrm{pH} 4$ and 6 Major and Minor Species

11. Adsorption Trends of Potassium Thiocyanate Species at the $\alpha-\mathrm{Al}_{2} \mathrm{O}_{3}(0001) / \mathrm{H}_{2} \mathrm{O}$ Interface

12. Angular Distribution Function of Aluminol Groups at the a- $\mathrm{Al}_{2} \mathrm{O}_{3}(0001) / \mathrm{H}_{2} \mathrm{O}$ Interface

13. Estimation of $\mathrm{SCN}^{-}$Surface Coverage Versus $\mathrm{pH}$ and Potassium Thiocyanate Concentration

14. SFG of KSCN in the OH Stretching Region

15. Comparison of Interfacial Water Structuring by KSCN to Halide Ions using vSFG

16. Comparison of Interfacial and Bulk $\mathrm{SCN}^{-}$Vibrational Frequencies

17. Coulomb Potential Versus Distance Using a Selection of Dielectric Constants

18. Simulated Eigenmodes of KSCN

19. Simulation of Interfacial KSCN SFG Spectra at the $\alpha-\mathrm{Al}_{2} \mathrm{O}_{3}(0001) / \mathrm{H}_{2} \mathrm{O}$ Interface

20. Snapshot of Potassium Thiocyanate at the $\mathrm{pH} 6 \alpha-\mathrm{Al}_{2} \mathrm{O}_{3}(0001) / \mathrm{H}_{2} \mathrm{O}$ Interface

21. S-H Radial Distribution Function for $\mathrm{SCN}^{-}$in Water and at the $\alpha-\mathrm{Al}_{2} \mathrm{O}_{3}(0001) / \mathrm{H}_{2} \mathrm{O}$ Interface

22. VDOS of KSCN Species at the $\alpha-\mathrm{Al}_{2} \mathrm{O}_{3}(0001) / \mathrm{H}_{2} \mathrm{O}$ Interface and in Bulk Water

23. References

\section{Additional Sample Preparation Details}

Alumina equilateral roof prisms $(15 \times 13 \times 13 \times 15 \mathrm{~mm})$, with the $\alpha-\mathrm{Al}_{2} \mathrm{O}_{3}(0001)$ cut exposed, were purchased from Team Photon Inc. (San Diego, CA). These prisms provided the alumina surfaces in our experiments. These prisms were first cleaned with "piranha" solution ( 1 volume concentrated $\mathrm{H}_{2} \mathrm{O}_{2}: 3$ volume concentrated $\mathrm{H}_{2} \mathrm{SO}_{4}$ ) for $\sim 30 \mathrm{~min}$ in a circular Teflon dish. (CAUTION: "piranha is extremely reactive and can cause severe damage to skin/eyes. Handle using gloves, googles, a lab coat, and extreme care.) It is important to remove any remaining piranha solution as the acidic nature of the piranha solution can affect the working surface. To ensure that no residual piranha remained, the prisms were rinsed with deionized water $(>18.2$ $M^{\prime} \Omega / \mathrm{cm}$ resistivity, Thermoscientific Barnstead Easypure II purification system with UV lamp) for no less than ten minutes, and then dried using ultra high purity $\mathrm{N}_{2}$ gas. Lastly, the custom made sample holder containing a Teflon O-ring and a prism are cleaned using low-pressure RF plasma for $\sim 30$ min (Harrick PDC-32G). Components of the sample apparatus then equilibrate to room temperature under vacuum before being exposed to deionized water for $\sim 15$ minutes prior to any experimental measurements. 


\section{Additional Computational Details}

We followed a similar approach with $\mathrm{KSCN}$ in bulk water as we did for KSCN at the alumina surface, including the same force fields and general procedure, starting from a low-density system with $128 \mathrm{H}_{2} \mathrm{O}$ molecules, $1 \mathrm{KSCN}$ pair, and a box length of $50 \AA$. We ran NVT and then NPT simulations for $1 \mathrm{~ns}$, next we deformed the box to $15.76 \AA$ over $1 \mathrm{~ns}$, and finally equilibrated the system in the NVT ensemble over $1 \mathrm{~ns}$. We then simulated the system using CPMD simulations for 1 ps in the NVT ensemble using the Nosé-Hoover thermostat in order to extract vibrational spectra.

All frequency calculations for isolated molecules were computed with Gaussian $16^{1}$ using the wB97xD ${ }^{2}$ functional and the aug-cc-pVTZ basis set ${ }^{3}$ after geometry optimization. All variants of the $\mathrm{SCN}^{-}$molecule, including that with $\mathrm{H}^{+}$or $\mathrm{D}^{+}$added, remained linear through the optimization process.

Note that we use the full correlation function in Equation 1 without any truncation of spatial correlations. Previous work has shown that these spatial correlations can take tens of picoseconds to converge and can strongly impact the shape of the SFG spectrum. ${ }^{4}$ However, we have shown that for the small simulation cells associated with ab-initio methods, the spatial correlations are truncated at relatively short distances, such that one can achieve well-converged spectra over shorter simulation times. ${ }^{5}$ In addition, we do not expect spatial correlations to strongly impact the spectra due to the $\mathrm{SCN}^{-}$molecule, because there are no other vibrational modes near the experimentally observed $\mathrm{SCN}^{-}$stretching frequency. We also include only one $\mathrm{SCN}^{-}$in our simulation cell, such that it is isolated from other $\mathrm{SCN}^{-}$molecules.

\section{Optical Setup}

Approximately 90\% of a Ti:Sapphire regenerative amplifier laser system (Coherent, LIBRA - F$1 \mathrm{~K}-110-\mathrm{HE}+$ ), generating $5 \mathrm{~mJ}$ pulses at $800 \mathrm{~nm}$ with a repetition rate of $1 \mathrm{kHz}$ and $120 \mathrm{fs}$ pulse duration pumps a commercial optical parametric amplifier (OPA)(Coherent, TOPAS-Prime HE). The $0.5 \mathrm{~mW}$ of Libra not steered towards the TOPAS OPA serves as the visible beam line. These $800 \mathrm{~nm}$ pulses pass through a narrow bandpass filter (CVI Laser Optics) resulting in $\sim 30 \mu \mathrm{J}$ pulses with $\sim 2 \mathrm{~nm}$ of bandwidth $\left(\sim 30 \mathrm{~cm}^{-1}\right)$. To generate tunable mid IR pulses in the $4000-1600 \mathrm{~cm}^{-1}$ region we used an external difference frequency generation (DFG) $\mathrm{AgGaS}_{2}$ crystal attached to the output of the TOPAS. To collect vSFG spectra over a region $\sim 250 \mathrm{~cm}^{-1}$ wide (defined by the $10 \%$ pedestal intensity level) in the $C \equiv N$ stretch region a broadband IR pulse profile is generated with $\sim 15 \mu \mathrm{J} /$ pulse centered at $\sim 2100 \mathrm{~cm}^{-1}$. The incident angles were $60^{\circ}$ (IR $\sim 15 \mu \mathrm{J} / \mathrm{pulse}$ ) and $54^{\circ}$ (visible $\sim 15 \mu \mathrm{J} /$ pulse) for the steady state $\mathrm{vSFG}$ measurements with focused beam radii of $\sim 75$ and $\sim 200 \mu \mathrm{m}$, respectively. Usually our experiments are performed with more bandwidth in the IR pulses, but the much lower concentration potassium thiocyanate solutions compared to bulk water required focusing all available IR pulse energy into a narrower spectral region $\left(250 \mathrm{~cm}^{-1}\right.$ pedestal 
width). The chosen angles of incidence are slightly above the critical angle for the $\alpha$ $\mathrm{Al}_{2} \mathrm{O}_{3}(0001) / \mathrm{H}_{2} \mathrm{O}$ interface to ensure that the total internal reflection (TIR) condition is met, which increases the magnitude of the collected VSFG signal. TIR geometry also ensures that we are primarily sampling the $\chi_{z z z}$ element of the total nonlinear susceptibility associated with PPP experimental geometry. ${ }^{6}$ The reflected SFG photons are separated from the scattered $800 \mathrm{~nm}$ photons with a $750 \mathrm{~nm}$ short pass filter (Melles Griot) and then dispersed onto a CCD detector array (model Princeton Instruments) which is coupled to a spectrograph (300i Acton Research Corp.).

\section{VSFG Data Normalization}

The steady-state vSFG spectral are normalized by division of the nonresonant vSFG signal generated from a gold coated $\alpha-\mathrm{Al}_{2} \mathrm{O}_{3}(0001)$ prism which accounts for the IR pulse profile and is then corrected by wavelength dependent Fresnel factors that account for the dispersion of the refractive index in the $\mathrm{OH}$ stretch region. This has been described in detail previously. ${ }^{6}$

\section{VSFG Spectra of $\mathrm{H}_{2} \mathrm{O}$ in the $\mathrm{CN}$ Stretching Region}

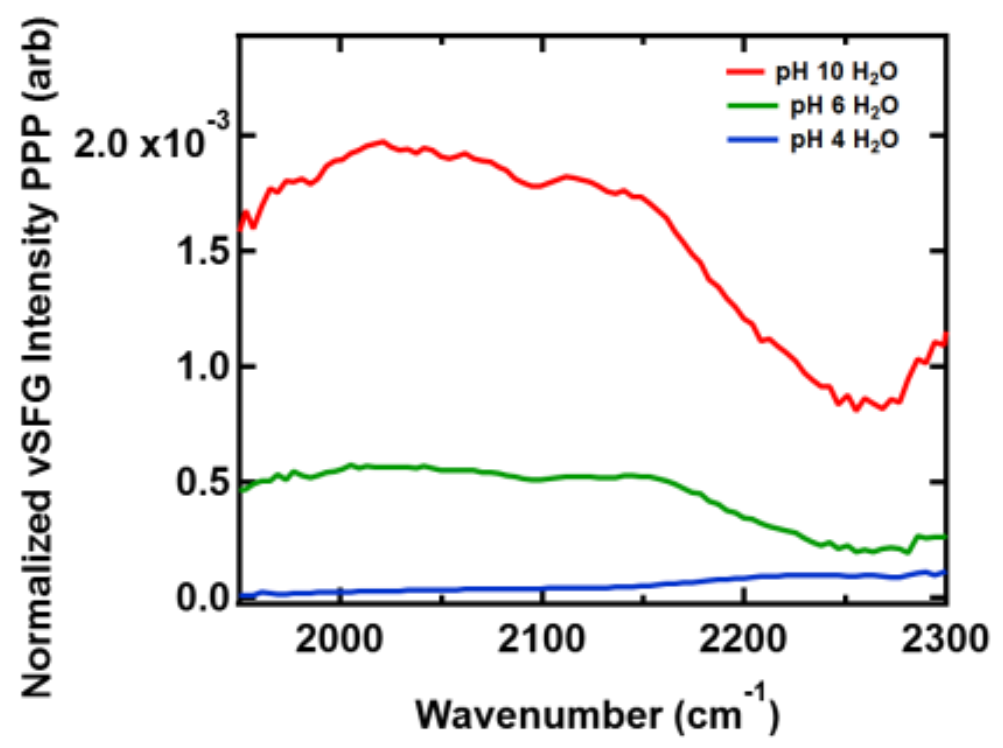

Figure S1: Normalized vSFG spectra of $\mathrm{pH} 4,6$, and $10 \mathrm{H}_{2} \mathrm{O}$ solutions in the $\mathrm{CN}$ stretching region taken using the PPP polarization combination. 


\section{Comparison of $1 \mathrm{M}$ KSCN and KCl solutions vSFG Spectra in the CN Stretching Region}

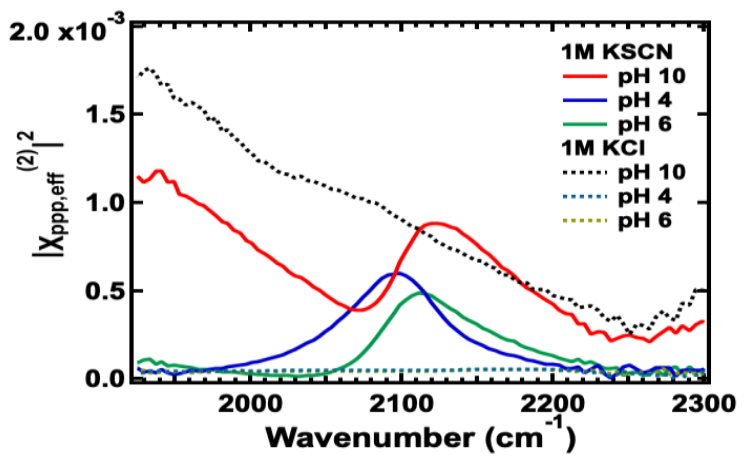

Figure S2: Normalized vSFG spectra of $\mathrm{pH} 4,6$, and $101 \mathrm{M} \mathrm{KSCN}$ and $\mathrm{KCl}$ solutions in the $\mathrm{CN}$ stretching region taken using PPP the polarization combination.

\section{Individual vSFG Spectra of $\mathrm{KSCN}$ at the $\alpha-\mathrm{Al}_{2} \mathrm{O}_{3}(0001) / \mathrm{H}_{2} \mathrm{O}$ Interface}

A

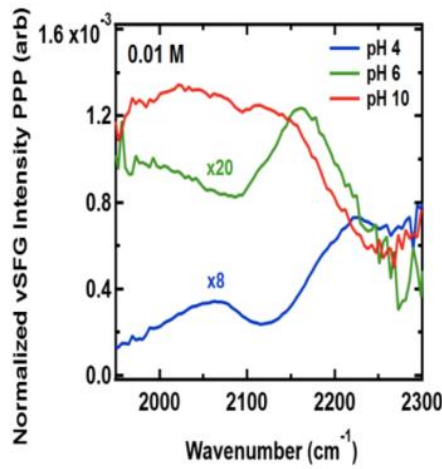

D

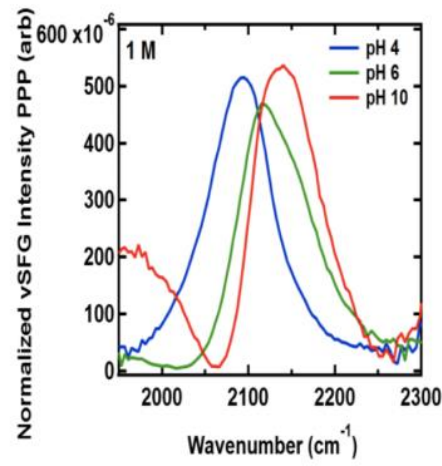

B

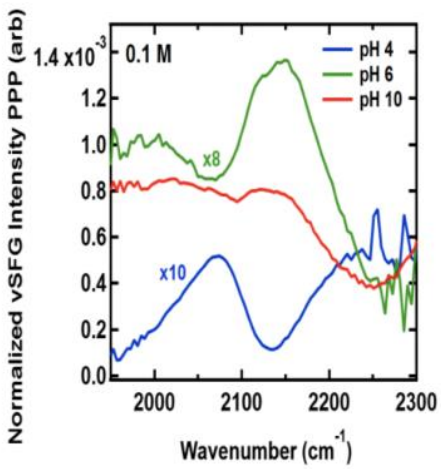

$\mathrm{E}$

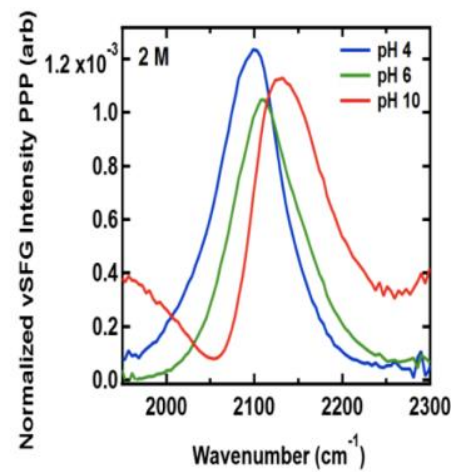

$\mathrm{C}$

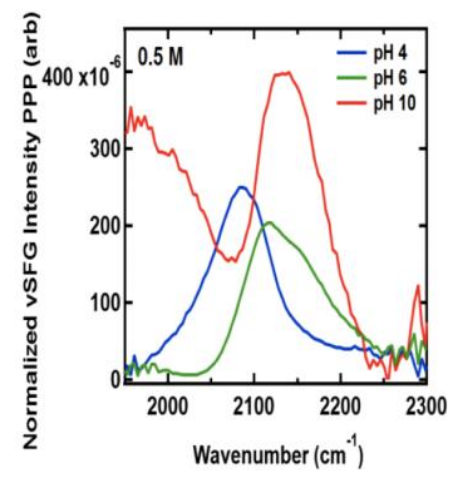

$\mathrm{F}$

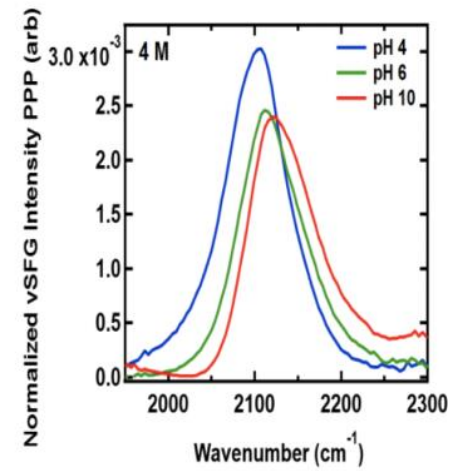

Figure S3: vSFG spectra of 0.01-4 M KSCN solutions (A-F) at the $\alpha-\mathrm{Al}_{2} \mathrm{O}_{3}(0001) / \mathrm{H}_{2} \mathrm{O}$ Interface. A small negative offset has been applied to $\mathrm{pH} 10 \mathrm{KSCN}$ spectra due to the enhanced nonresonant contribution to the spectra at $\mathrm{pH} 10$ in panels A-D for easier comparison of resonant features. 


\section{Simulation of One and Two Lorentzian Oscillators in the CN Stretching Region}

A
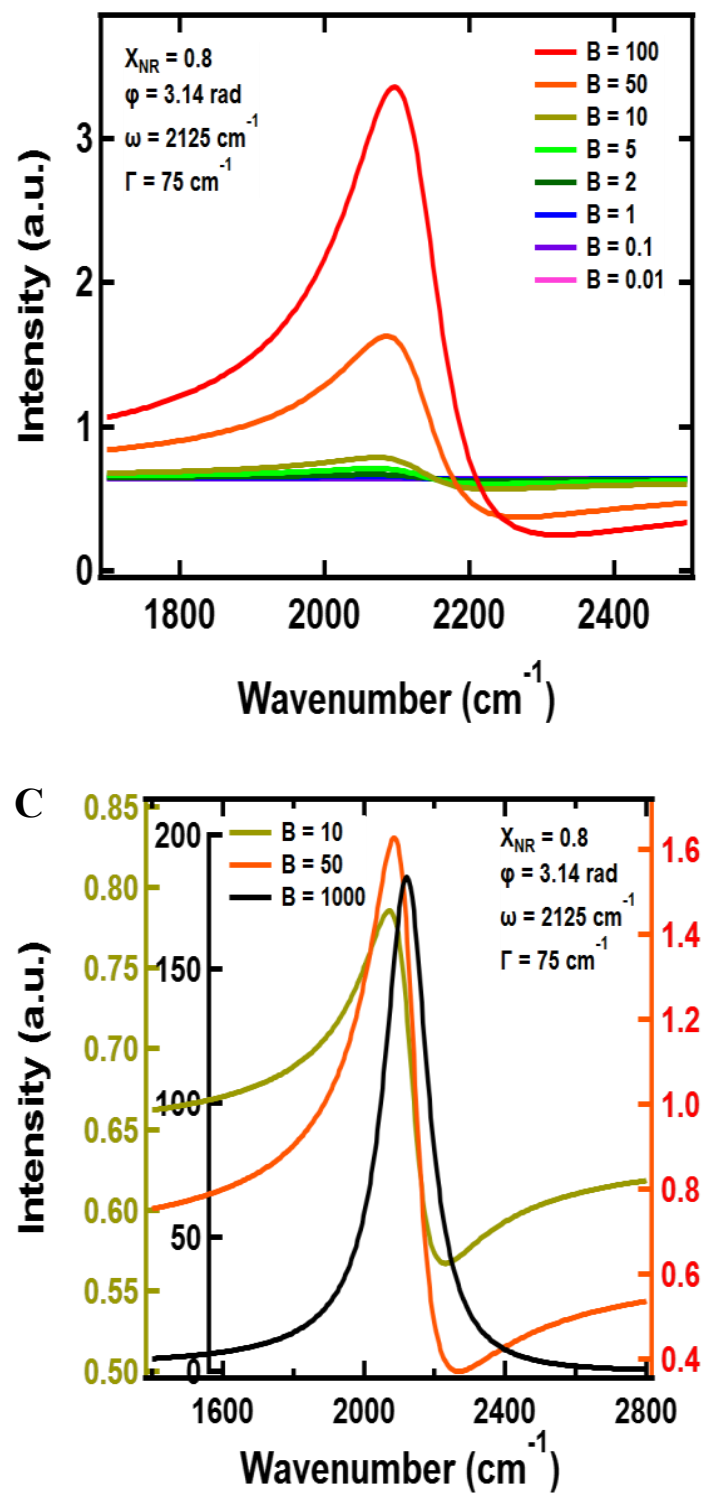

B

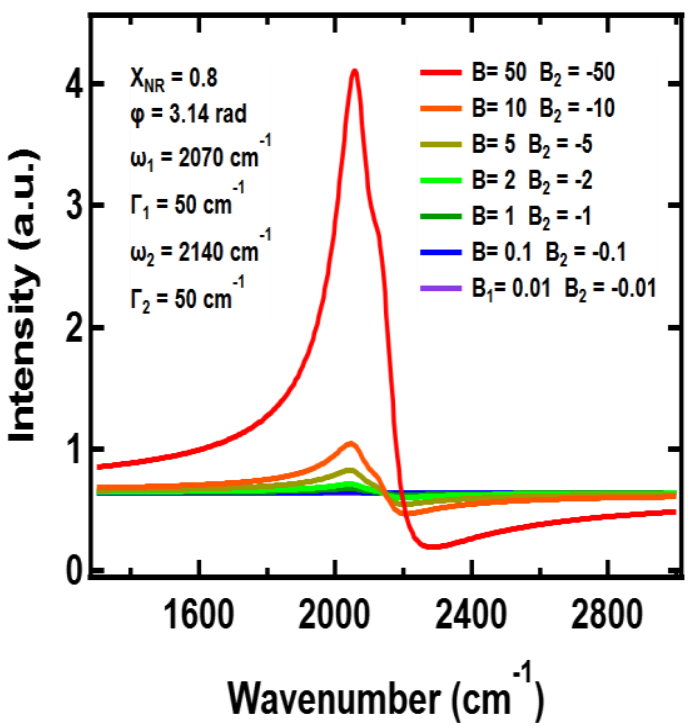

D

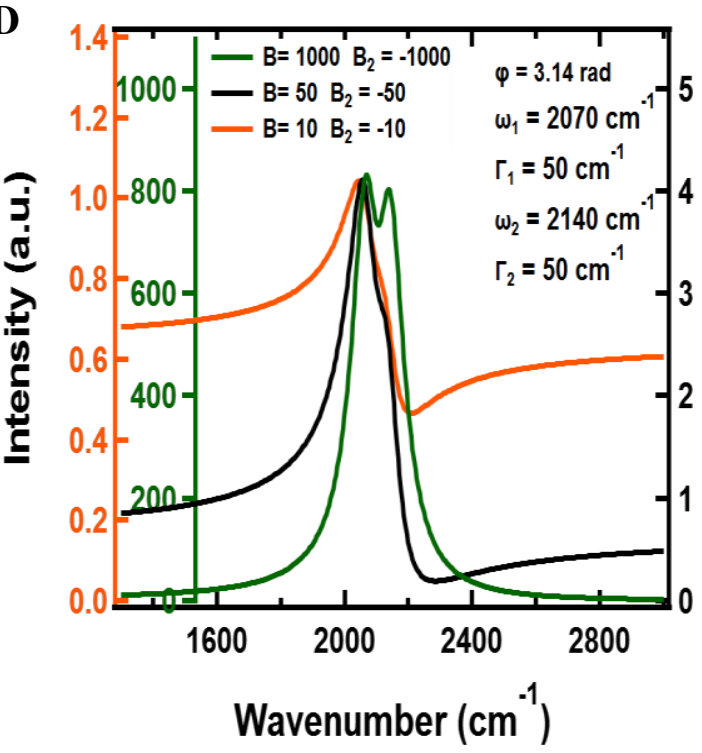

Figure S4: Simulation of second order line shapes using Equation 3 for one oscillator $(\mathbf{A}, \mathbf{C})$ and two oscillators of opposite amplitude (B, D). Panels C-D show spectra plotted on individual vertical axes for easier qualitative comparison of the generated lineshapes. Note similar lineshapes can be acquired with careful choice of parameters for both one and two resonant oscillators. 


\section{Total Fits and Extracted Fit Parameters for Steady State KSCN vSFG Spectra}

A

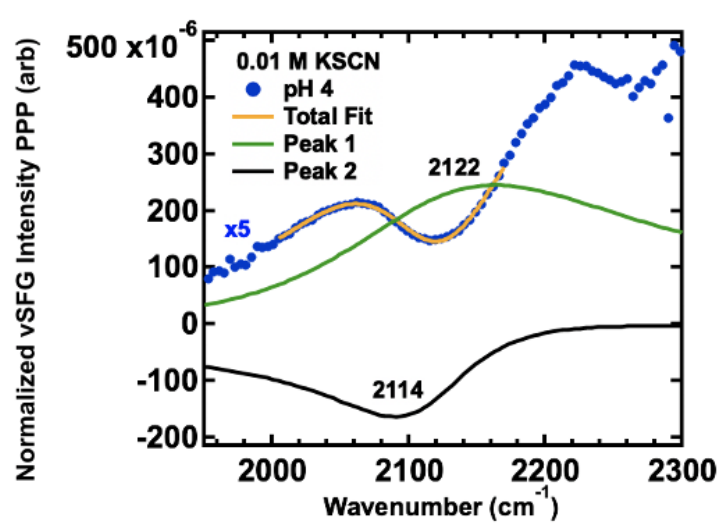

$\mathrm{C}$

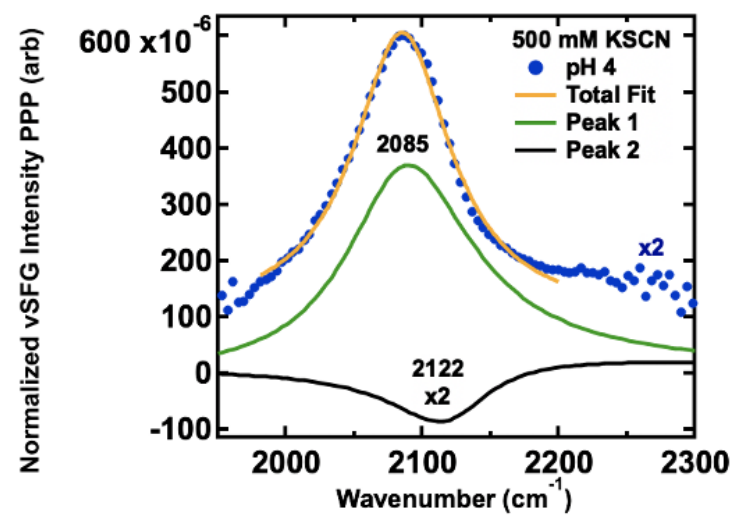

$\mathrm{E}$

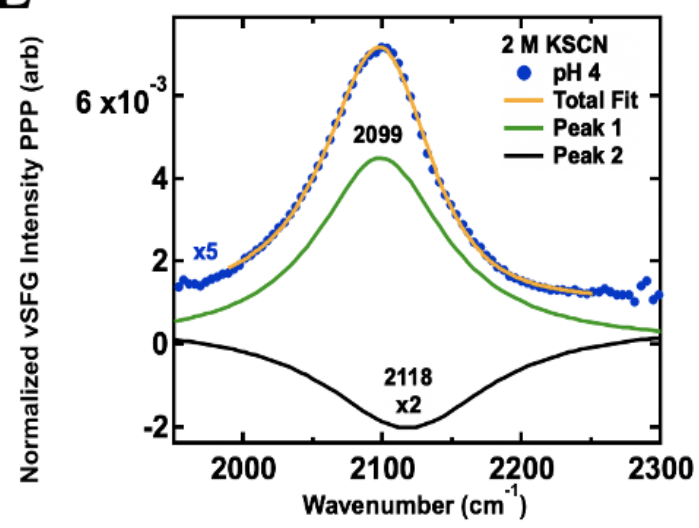

B

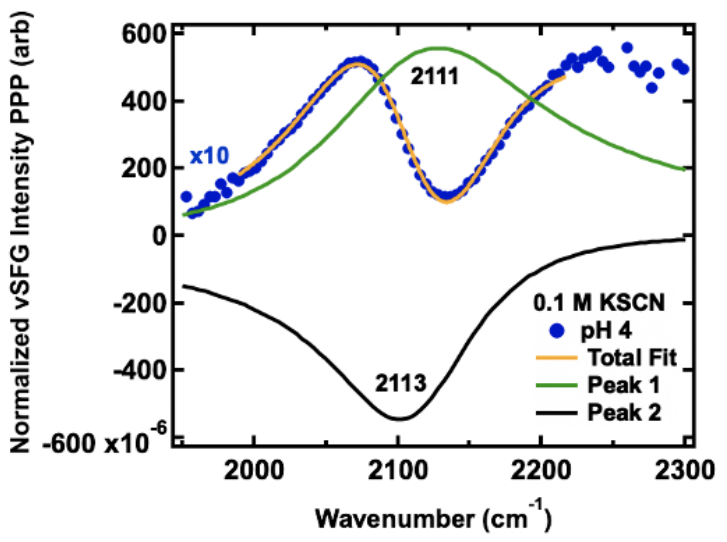

$\mathrm{D}$

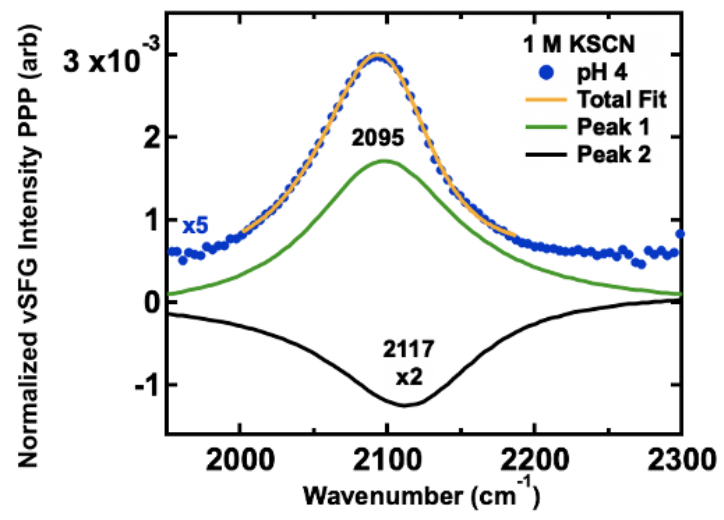

$\mathrm{F}$

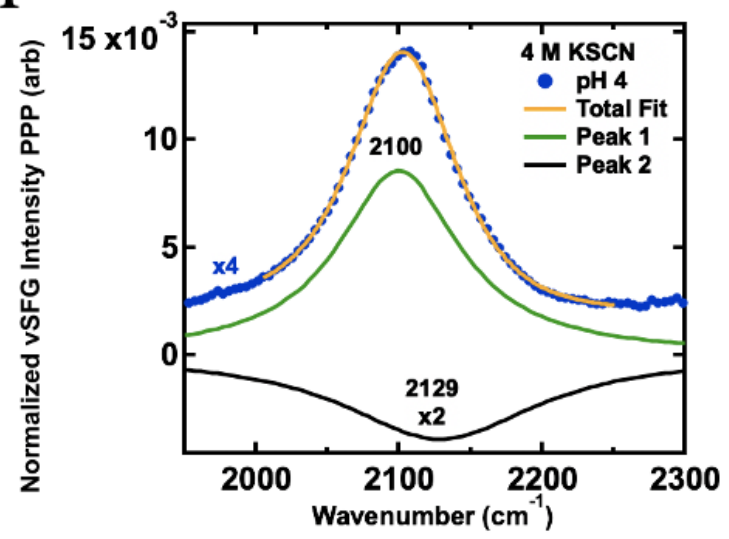

Figure S5: vSFG spectra of $0.01-4 \mathrm{M} \mathrm{pH} 4 \mathrm{KSCN}$ solutions (A-F) at the $\alpha-\mathrm{Al}_{2} \mathrm{O}_{3}(0001) / \mathrm{H}_{2} \mathrm{O}$ Interface including the total fit using equation 3. The individual Lorentzian peaks generated from fitting using equation $\mathbf{3}$ (also shown in Figure 4) are also displayed. 
A

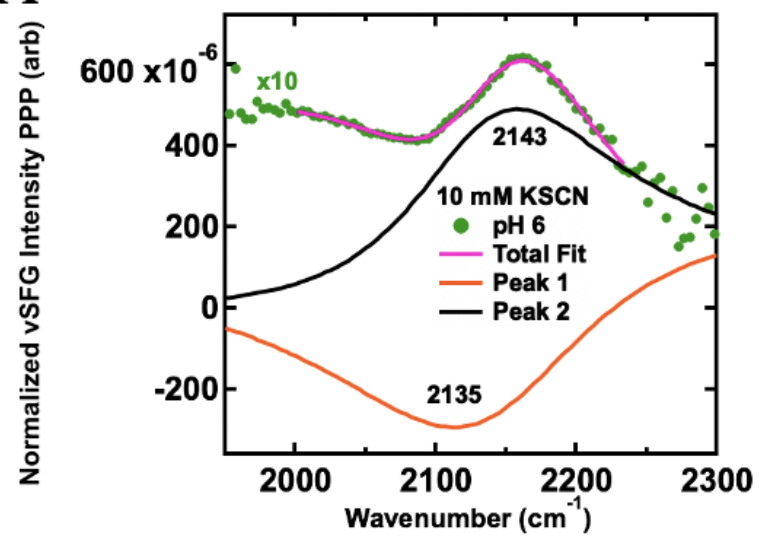

$\mathrm{C}$

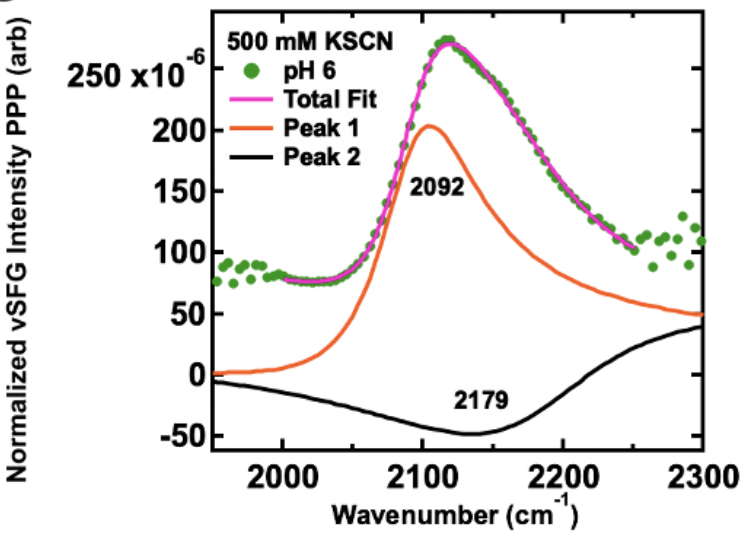

$\mathrm{E}$

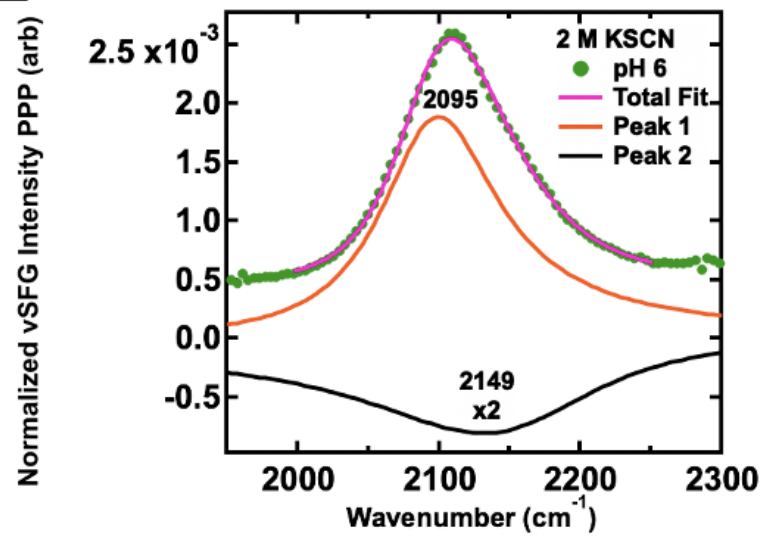

B

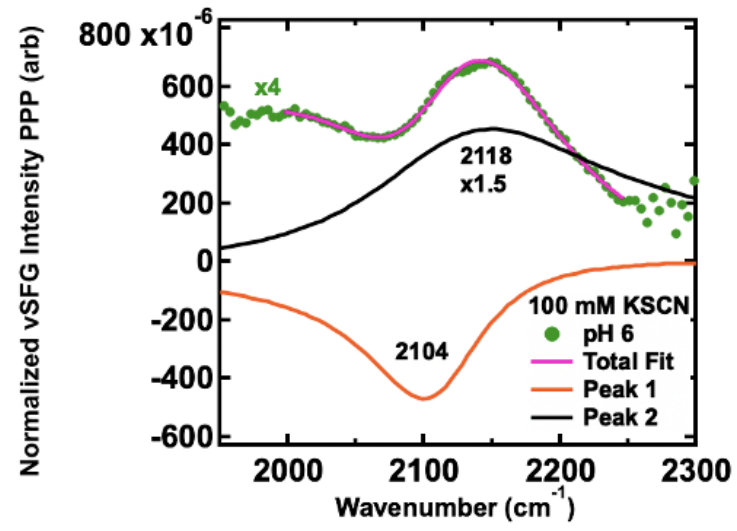

$\mathrm{D}$

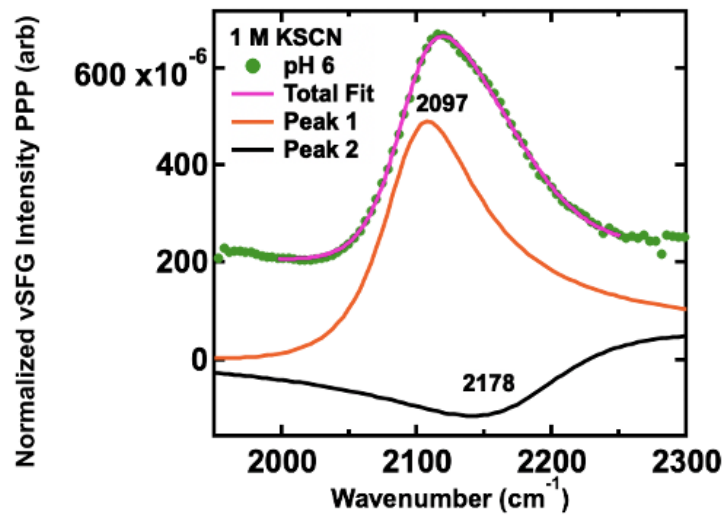

$\mathrm{F}$

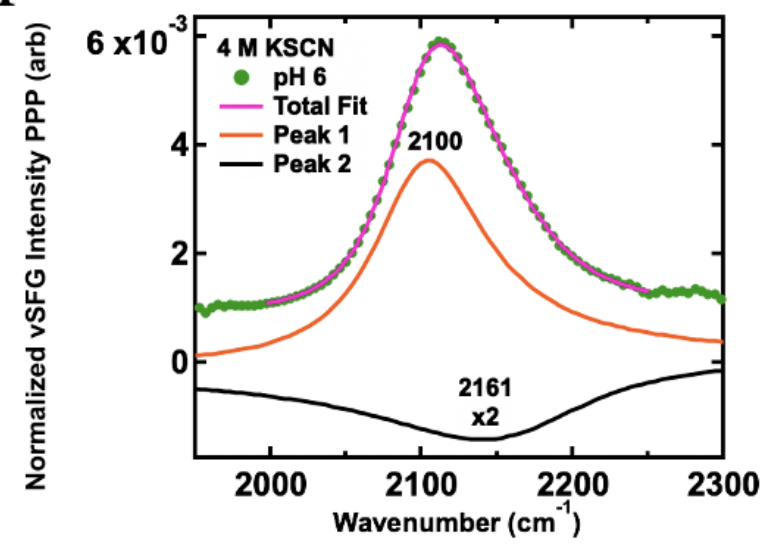

Figure S6: vSFG spectra of 0.01-4 M pH $6 \mathrm{KSCN}$ solutions (A-F) at the $\alpha-\mathrm{Al}_{2} \mathrm{O}_{3}(0001) / \mathrm{H}_{2} \mathrm{O}$ Interface including the total fit using equation 3. The individual Lorentzian peaks generated from fitting using equation $\mathbf{3}$ (also shown in Figure 4) are also displayed. 
A

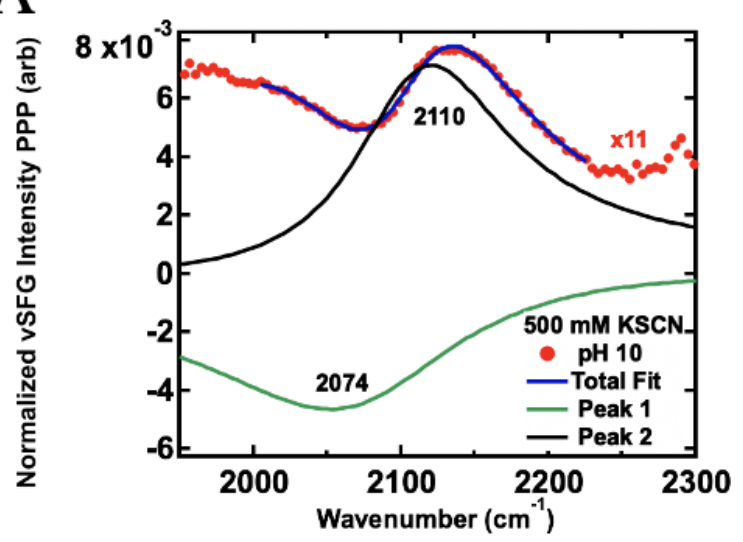

C

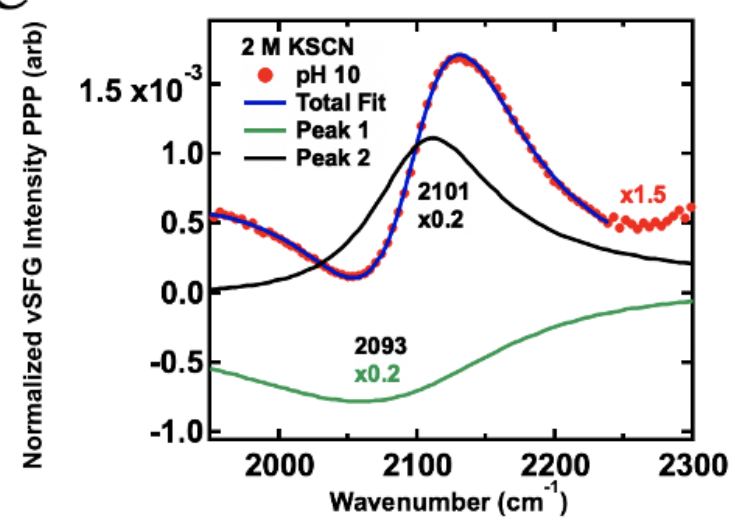

B

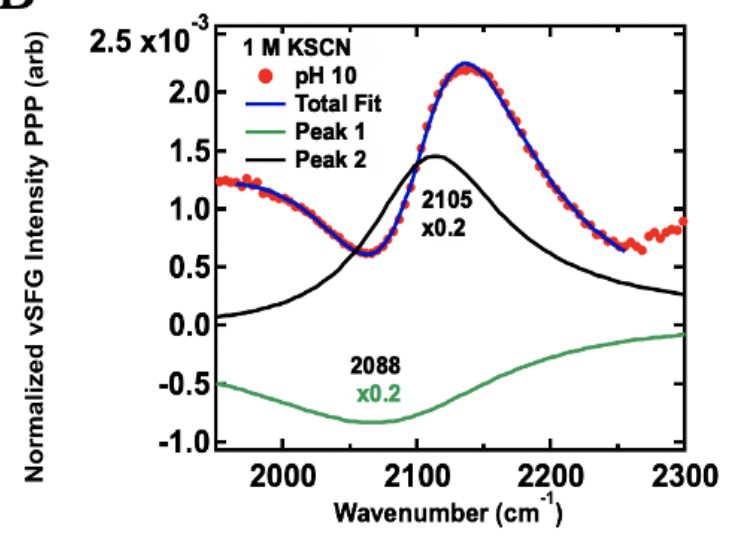

$\mathrm{D}$

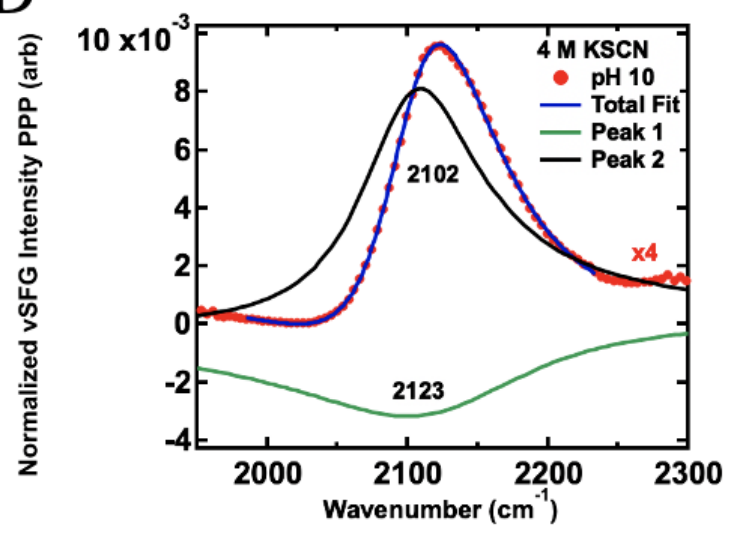

Figure S7: vSFG spectra of $0.5-4 \mathrm{M} \mathrm{pH} 10 \mathrm{KSCN}$ solutions (A-F) at the $\alpha-\mathrm{Al}_{2} \mathrm{O}_{3}(0001) / \mathrm{H}_{2} \mathrm{O}$ Interface including the total fit using equation 3. The individual Lorentzian peaks generated from fitting using equation $\mathbf{3}$ (also shown in Figure 4) are also displayed. 


\begin{tabular}{|c|c|c|c|c|c|c|c|c|c|c|c|c|}
\hline & \multicolumn{12}{|c|}{ pH $4 \mathrm{KSCN}$ at the $\alpha-\mathrm{Al}_{2} \mathrm{O}_{3}(0001) / \mathrm{H}_{2} \mathrm{O}$ Interface } \\
\hline & \multicolumn{2}{|c|}{$\begin{array}{c}10 \mathbf{~ m M} \\
\text { Chisq }=1.0 \mathrm{x} \\
10^{-11}\end{array}$} & \multicolumn{2}{|c|}{$\begin{array}{c}\mathbf{0 . 1} \mathbf{M} \\
\text { Chisq }=6.2 \mathrm{x} \\
10^{-11}\end{array}$} & \multicolumn{2}{|c|}{$\begin{array}{c}\mathbf{0 . 5} \mathbf{M} \\
\text { Chisq }=1.5 \mathrm{x} \\
10^{-10}\end{array}$} & \multicolumn{2}{|c|}{$\begin{array}{c}\mathbf{1 ~ M} \\
\text { Chisq }=2.0 \mathrm{x} \\
10^{-9}\end{array}$} & \multicolumn{2}{|c|}{$\begin{array}{c}2 \mathbf{M} \\
\text { Chisq }=8.8 \times \\
10^{-9}\end{array}$} & \multicolumn{2}{|c|}{$\begin{array}{c}\mathbf{4 M} \\
\text { Chisq }=3.1 \mathrm{x} \\
10^{-8}\end{array}$} \\
\hline Species & Maj & Min & Maj & Min & Maj & Min & Maj & Min & Maj & Min & Maj & Min \\
\hline$\omega_{v}\left(\mathrm{~cm}^{-1}\right)$ & 2122 & 2114 & 2111 & 2113 & 2085 & 2122 & 2095 & 2117 & 2099 & 2118 & 2100 & 2129 \\
\hline$\phi(\mathrm{rad})$ & \multicolumn{2}{|c|}{0} & \multicolumn{2}{|c|}{0} & \multicolumn{2}{|c|}{0} & \multicolumn{2}{|c|}{0} & \multicolumn{2}{|c|}{0} & \multicolumn{2}{|c|}{0} \\
\hline$A_{v}($ arb $)$ & 1.9 & -0.7 & 2.1 & -1.4 & 1.1 & -0.3 & 2.5 & -1.5 & 3.7 & -2.6 & 4.8 & -3.7 \\
\hline$\Gamma_{v}\left(\mathrm{~cm}^{-1}\right)$ & 134 & 64 & 92 & 62 & 56 & 43 & 60 & 60 & 56 & 72 & 52 & 83 \\
\hline $\begin{array}{l}\chi_{N R} \\
\text { (arb) }\end{array}$ & \multicolumn{2}{|c|}{$5 \times 10^{-3}$} & \multicolumn{2}{|c|}{$4.3 \times 10^{-3}$} & \multicolumn{2}{|c|}{$1.5 \times 10^{-3}$} & \multicolumn{2}{|c|}{$2.3 \times 10^{-3}$} & \multicolumn{2}{|c|}{0} & \multicolumn{2}{|c|}{0} \\
\hline
\end{tabular}

Table S1: Lorentzian peak parameters for $\mathrm{pH} 4$ data (blue traces) in Figure 2. Maj and Min refer to major and minor species extracted from fitting the steady-state vSFG data. All spectra require two closely spaced resonant modes with opposite amplitude to achieve high quality fitting. The individual oscillators extracted from fitting are graphically represented in Figure 4 A-B.

\begin{tabular}{|c|c|c|c|c|c|c|c|c|c|c|c|c|}
\hline & \multicolumn{12}{|c|}{ pH $6 \mathrm{KSCN}$ at the $\alpha-\mathrm{Al}_{2} \mathrm{O}_{3}(0001) / \mathrm{H}_{2} \mathrm{O}$ Interface } \\
\hline & \multicolumn{2}{|c|}{$\begin{array}{c}10 \mathbf{~ m M} \\
\text { Chisq }=3.3 \mathrm{x} \\
10^{-11}\end{array}$} & \multicolumn{2}{|c|}{$\begin{array}{c}\mathbf{0 . 1} \mathbf{M} \\
\text { Chisq }=2.6 \mathrm{x} \\
10^{-10}\end{array}$} & \multicolumn{2}{|c|}{$\begin{array}{c}\mathbf{0 . 5} \mathbf{M} \\
\text { Chisq }=3.0 \mathrm{x} \\
10^{-10}\end{array}$} & \multicolumn{2}{|c|}{$\begin{array}{c}\mathbf{1} \mathbf{M} \\
\text { Chisq }=1.3 \mathrm{x} \\
10^{-9} \\
\end{array}$} & \multicolumn{2}{|c|}{$\begin{array}{c}\mathbf{2} \mathbf{M} \\
\text { Chisq }=7.0 \mathrm{x} \\
10^{-9} \\
\end{array}$} & \multicolumn{2}{|c|}{$\begin{array}{c}\mathbf{4} \mathbf{M} \\
\text { Chisq }=1.9 \mathrm{x} \\
10^{-8}\end{array}$} \\
\hline Species & Maj & Min & Maj & Min & Maj & Min & Maj & Min & Maj & Min & Maj & Min \\
\hline$\omega_{v}\left(\mathrm{~cm}^{-1}\right)$ & 2135 & 2143 & 2104 & 2118 & 2092 & 2179 & 2097 & 2178 & 2095 & 2149 & 2100 & 2161 \\
\hline$\phi(\mathrm{rad})$ & \multicolumn{2}{|c|}{0} & \multicolumn{2}{|c|}{0} & \multicolumn{2}{|c|}{0} & \multicolumn{2}{|c|}{0} & \multicolumn{2}{|c|}{0} & \multicolumn{2}{|c|}{0} \\
\hline$A_{v}(\mathrm{arb})$ & 1.9 & -2.4 & 1.9 & -3.3 & 0.56 & -0.79 & 0.88 & -0.84 & 2.2 & -1.9 & 2.7 & -2.2 \\
\hline$\Gamma_{v}\left(\mathrm{~cm}^{-1}\right)$ & 91 & 107 & 80 & 112 & 43 & 100 & 43 & 79 & 50 & 99 & 45 & 86 \\
\hline$\chi_{N R}($ arb) & \multicolumn{2}{|c|}{$5.9 \times 10^{-3}$} & \multicolumn{2}{|c|}{$8.1 \times 10^{-3}$} & \multicolumn{2}{|c|}{$4.4 \times 10^{-3}$} & \multicolumn{2}{|c|}{$6.0 \times 10^{-3}$} & \multicolumn{2}{|c|}{$3.7 \times 10^{-3}$} & \multicolumn{2}{|c|}{$6.3 \times 10^{-3}$} \\
\hline
\end{tabular}


Table S2: Lorentzian peak parameters for $\mathrm{pH} 6$ data (green traces) in Figure 2. Maj and Min refer to major and minor species extracted from fitting the steady-state VSFG data. The major and minor spectral contributions are spaced by $\sim 60 \mathrm{~cm}^{-1}$. The individual oscillators extracted from fitting are graphically represented in Figure 4 A-B.

\begin{tabular}{|c|c|c|c|c|c|c|c|c|}
\hline & \multicolumn{8}{|c|}{ pH $10 \mathrm{KSCN}$ at the $\alpha-\mathrm{Al}_{2} \mathrm{O}_{3}(0001) / \mathrm{H}_{2} \mathrm{O}$ Interface } \\
\hline & \multicolumn{2}{|c|}{$\begin{array}{c}\mathbf{0 . 5} \mathbf{~ M} \\
\text { Chisq }=2.4 \times 10^{-9}\end{array}$} & \multicolumn{2}{|c|}{$\begin{array}{c}\mathbf{1} \mathbf{M} \\
\text { Chisq }=4.8 \times 10^{-9}\end{array}$} & \multicolumn{2}{|c|}{$\begin{array}{c}\mathbf{2} \mathbf{M} \\
\text { Chisq }=1.1 \times 10^{-8}\end{array}$} & \multicolumn{2}{|c|}{$\begin{array}{c}\mathbf{4 ~ \mathbf { M }} \\
\text { Chisq }=1.4 \times 10^{-8}\end{array}$} \\
\hline Species & Maj & Min & Maj & Min & Maj & Min & Maj & Min \\
\hline$\omega_{v}\left(\mathrm{~cm}^{-1}\right)$ & 2110 & 2074 & 2105 & 2088 & 2101 & 2093 & 2102 & 2123 \\
\hline$\phi(\mathrm{rad})$ & \multicolumn{2}{|l|}{0} & \multicolumn{2}{|l|}{0} & \multicolumn{2}{|l|}{0} & \multicolumn{2}{|l|}{0} \\
\hline$A_{v}($ arb) & 5.2 & -6.7 & 5 & -7.1 & 3.8 & -5.8 & 4.6 & -5.6 \\
\hline$\Gamma_{v}\left(\mathrm{~cm}^{-1}\right)$ & 64 & 103 & 60 & 114 & 53 & 123 & 52 & 105 \\
\hline$\chi_{N R}$ (arb) & \multicolumn{2}{|c|}{$1.4 \times 10^{-2}$} & \multicolumn{2}{|c|}{$1.2 \times 10^{-2}$} & \multicolumn{2}{|c|}{$1.4 \times 10^{-2}$} & \multicolumn{2}{|c|}{$1.2 \times 10^{-2}$} \\
\hline
\end{tabular}

Table S3: Lorentzian peak parameters for $\mathrm{pH} 10$ data (red traces) in Figure 2. Maj and Min refer to major and minor species extracted from fitting the steady-state vSFG data. Again, the minor species central frequency, $\omega_{\mathrm{v}}$, is not concentration dependent. The individual oscillators extracted from fitting are graphically represented in Figure 4 AB.

\section{Langmuir Adsorption Isotherms of pH 4 and 6 Major and Minor Species}

To determine the free energy of adsorption, $\Delta \mathrm{G}_{\text {Ads, }}$, the extracted major and minor amplitudes $\left(\left|A_{S C N^{-}}\right|\right)$in Figure 5, were fit with a simple Langmuir adsorption function (Equation S1). The extracted absolute values of the amplitudes of the $\mathrm{pH} 4$ and $\mathrm{pH} 6$ major and minor species were used as the observable in the form of $\theta\left(\left[\chi_{b u l k, S C N^{-}}\right]\right)$, where $\theta$ is represented by $\left|A_{S C N^{-}}\right| /$ $\left|A_{\text {maxSCN}}\right|$.

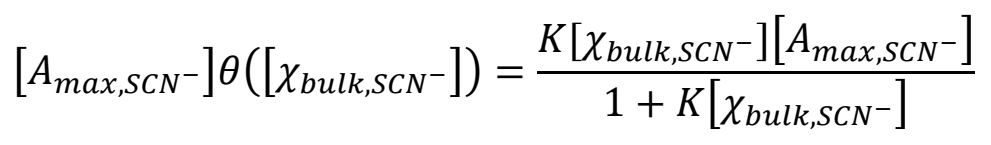


Here $\chi_{\text {bulk,SCN}}$ is the bulk mole fraction, $\theta$ is the surface coverage, $\left[A_{\max , S C N^{-}}\right]$is the amplitude reflecting monolayer coverage is reached, and $\mathrm{K}$ is the equilibrium constant. The extracted equilibrium constants are then related to the $\Delta \mathrm{G}_{\mathrm{Ads}}$ using Equation S2:

$$
\Delta \mathrm{G}_{A d s}=-R T \ln K
$$

where $\mathrm{R}$ is the universal gas constant $\left(8.314 \frac{\mathrm{J}}{\mathrm{Kmol}}\right)$ and $\mathrm{T}$ is the temperature.

A

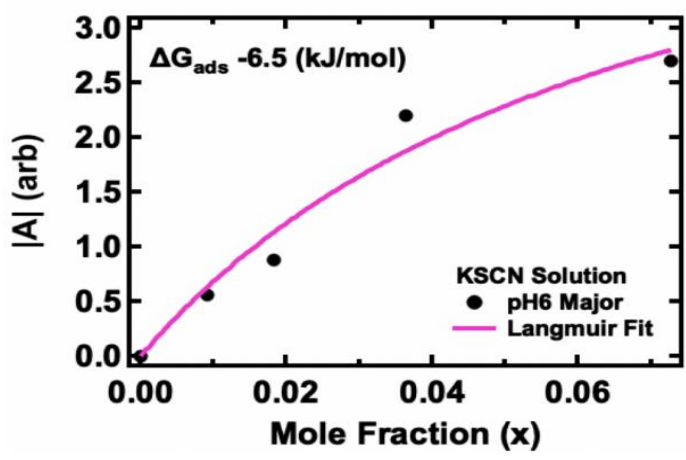

C

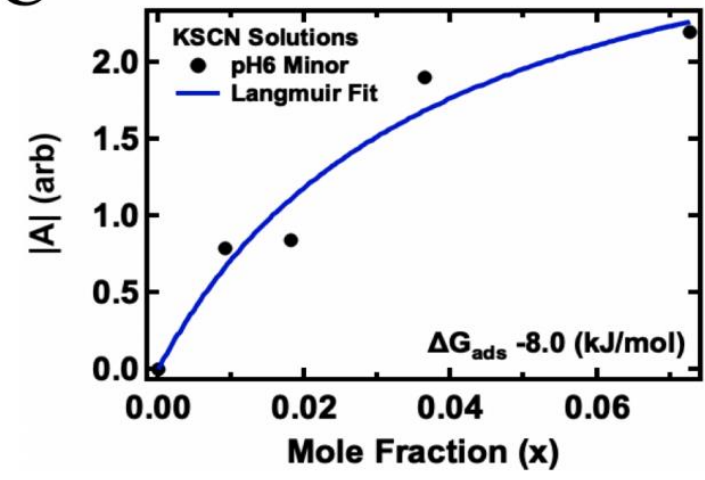

B

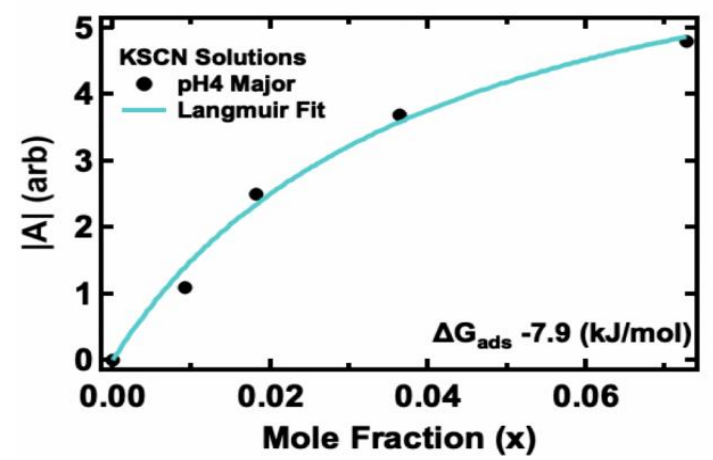

$\mathrm{D}$

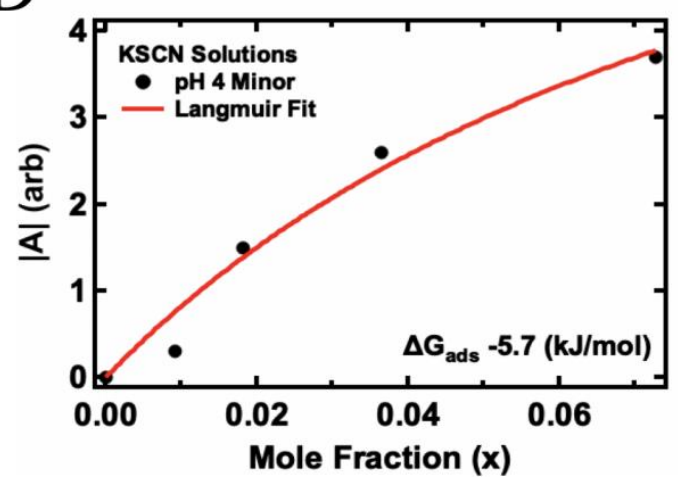

Figure S8: Langmuir adsorption isotherms generated from the extracted amplitudes of the pH 4 and 6 (A-B) major and (C-D) minor species. The absolute value of the $\mathrm{pH} 4$ and $\mathrm{pH} 6$ minor and major amplitudes are unique to each species and these tabulated values can be found in tables S1 and S2. pH 10 major and minor species were not fit using because the amplitude appears to be saturated at all concentrations tested.

\begin{tabular}{|l|l|l|l|}
\hline Species & $\Delta \mathbf{G}_{\text {Ads }}(\mathbf{k J} / \mathbf{m o l})$ & $\left|A_{\max , S C N^{-}}\right|$ & $\mathbf{K}\left(\mathbf{M}^{-1}\right)$ \\
\hline pH 6 Major & -6.5 & 5.5 & 14.1 \\
\hline
\end{tabular}




\begin{tabular}{|l|l|l|l|}
\hline pH 4 Major & -7.9 & 7.6 & 24.7 \\
\hline pH 6 Minor & -8.0 & 3.5 & 26 \\
\hline pH 4 Minor & -5.7 & 8.9 & 10.2 \\
\hline
\end{tabular}

Table S4: Extracted free energies of adsorption, maximum surface coverage intensities, and equilibrium constants for $\mathrm{pH} 4$ and pH 6 major and minor species. The values were extracted from the fits shown in Figure S8.

11. Adsorption Trends of Potassium Thiocyanate Species at the $\alpha-\mathrm{Al}_{2} \mathrm{O}_{3}(0001) / \mathrm{H}_{2} \mathrm{O}$ Interface

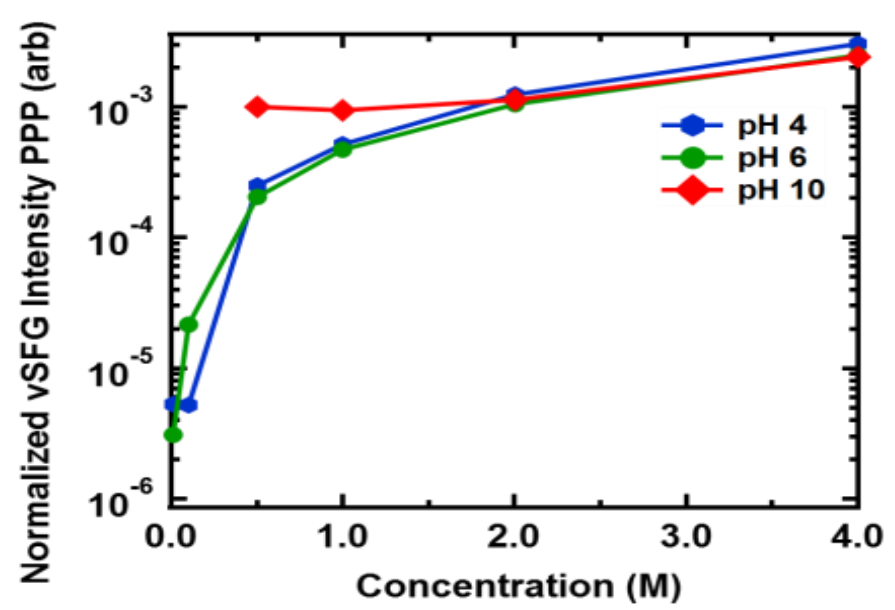

Figure S9: Amplitude of the most prominent feature in Figure S1 from inspection of Figure 1. PH 10 spectra do not have an obvious resonant feature larger than the nonresonant background for concentrations in the 0.01-0.1 M range.

12. Angular Distribution Function of Aluminol Groups at the $\alpha-\mathrm{Al}_{2} \mathrm{O}_{3}(0001) / \mathrm{H}_{2} \mathrm{O}$ Interface 


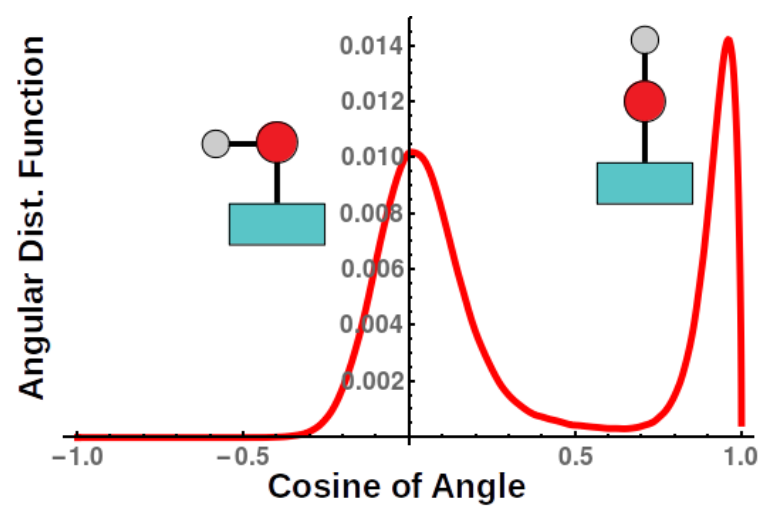

Figure S10: Angular distribution function corresponding to aluminol groups (surface $\mathrm{OH}$ ) present at the $\alpha-\mathrm{Al}_{2} \mathrm{O}_{3}(0001) / \mathrm{H}_{2} \mathrm{O}$ interface. The integrated angular distribution function yields a ratio of $\sim 40 \% / 60 \%$ for inplane/out-of-plane aluminol groups, respectively.

\section{Estimation of $\mathrm{SCN}^{-}$Surface Coverage Versus $\mathrm{pH}$ and Potassium Thiocyanate Concentration}

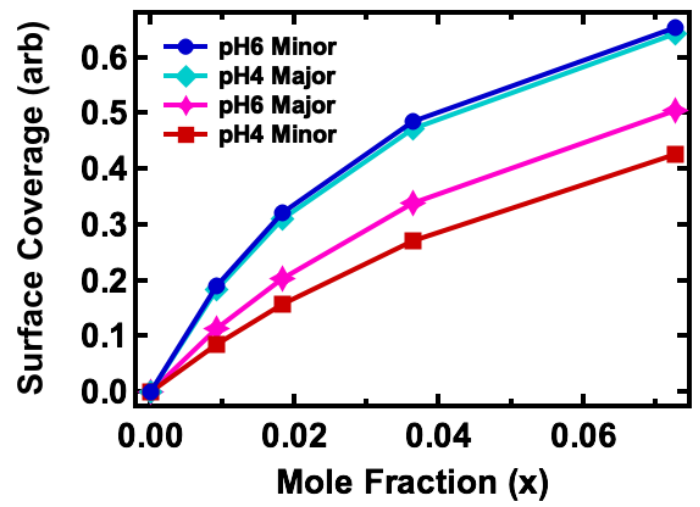

Figure S11: Estimated surface coverage of $\mathrm{SCN}^{-}$reporter molecules versus $\mathrm{pH}$ and potassium thiocyanate concentration. A surface coverage value of 1 denotes a complete monolayer has formed.

Rearranging equation S1 allows for plotting of the estimated surface coverage of $\mathrm{SCN}^{-}$ reporter molecules at a given $\mathrm{pH}$ and $\mathrm{KSCN}$ concentration. A value for $\theta$ of 1 represents the formation of a complete monolayer of $\mathrm{SCN}^{-}$. While the experimentally determined surface density of a complete $\mathrm{SCN}^{-1}$ monolayer at the $\alpha-\mathrm{Al}_{2} \mathrm{O}_{3}(0001) / \mathrm{H}_{2} \mathrm{O}$ interface is unknown, we can approximate the surface density of the monolayer by comparing to the packing density of thiocyanate self-assembled-monolayers (SAMS). For thiocyanate SAMS the nominal packing density is $\sim 1.4$ per $\mathrm{nm}$, or $\sim 1.9$
refers to bulkier alkyl chains with thiocyanate chains $/ \mathrm{nm}^{2}{ }^{7}$ Although this surface packing density refers to bulkier alkyl chains with thiocyanate
headgroups it is the closest comparison that can be made as the surface packing density of $\mathrm{SCN}^{-}$ ions at th $\alpha-\mathrm{Al}_{2} \mathrm{O}_{3}(0001) / \mathrm{H}_{2} \mathrm{O}$ interface is unknown. We can correlate the full packing density for thiocyanate SAMS as a value of 1 for $\theta$ (Equation S4).

$$
\theta\left(\left[\chi_{\text {bulk }}\right]\right) * \frac{1.96 S C N^{-}}{n m^{2}}=\frac{\text { Estimated } S C N^{2} \text { ions }}{n m^{2}}
$$

The estimated $\mathrm{SCN}^{-}$surface density can then be compared to the surface density of aluminol groups $\left(\sim 15 / \mathrm{nm}^{2}\right)^{8-9}$ and the estimated number of charged groups at $\mathrm{pH} 4(\sim 8 \%$ protonated 
aluminols) and $\mathrm{pH} 10$ ( $\sim \%$ deprotonated) which corresponds to 1.2 protonated aluminols $/ \mathrm{nm}^{2}$ at $\mathrm{pH} 4$ and 0.6 deprotonated aluminols $/ \mathrm{nm}^{2}$ at $\mathrm{pH} 10$, respectively. The estimated surface density of $\mathrm{SCN}^{-1}$ ions at experimental conditions can be found in Table $\mathbf{S 5}$.

\begin{tabular}{|c|c|c|c|c|c|}
\hline & & Estimated & $\begin{array}{r}\text { rface Density } \\
\text { (per }\end{array}$ & $\begin{array}{l}\text { f SCN- Repo } \\
\left.\mathbf{n m}^{2}\right)\end{array}$ & er Molecules \\
\hline $\begin{array}{l}\text { Concentration } \\
\text { (M) }\end{array}$ & $\begin{array}{l}\text { Concentration } \\
\text { (mole } \\
\text { fraction) }\end{array}$ & pH6 Major & pH 6 Minor & pH 4 Major & pH 4 Minor \\
\hline $\mathbf{0}$ & 0 & 0 & 0 & 0 & 0 \\
\hline 0.5 & 0.0091 & 0.22 & 0.37 & 0.36 & 0.17 \\
\hline 1 & 0.018 & 0.40 & 0.63 & 0.61 & 0.31 \\
\hline 2 & 0.036 & 0.66 & 0.95 & 0.93 & 0.53 \\
\hline 4 & 0.072 & 0.99 & 1.28 & 1.23 & 0.83 \\
\hline
\end{tabular}

Table S5: Estimated surface coverage of SCN $-\mathrm{nm}^{2}$ at the $\alpha-\mathrm{Al}_{2} \mathrm{O}_{3} / \mathrm{H}_{2} \mathrm{O}$ for our experimentally relevant conditions. Values obtained using equations $\mathbf{S 3}$ and $\mathbf{S 4}$. 


\section{SFG of KSCN in the OH Stretching Region}

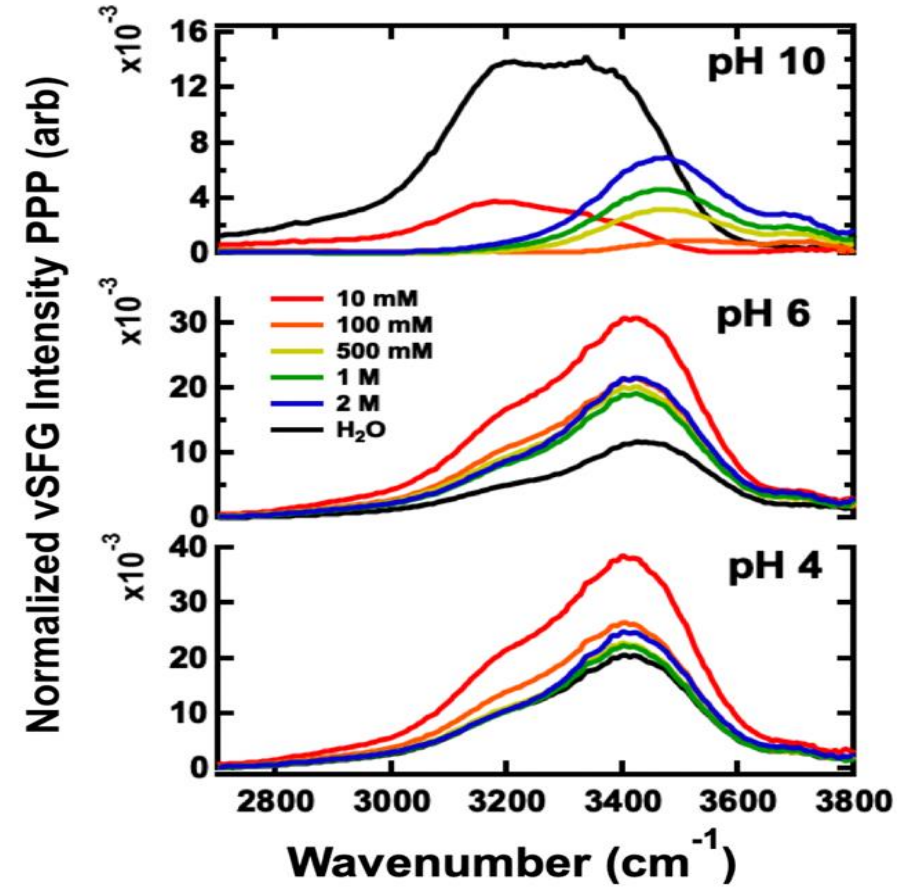

Figure S12: Concentration dependent vSFG spectra of KSCN solutions at the $\alpha-\mathrm{Al}_{2} \mathrm{O}_{3}(0001) / \mathrm{H}_{2} \mathrm{O}$ interface in the $\mathrm{O}-\mathrm{H}$ stretching region taken using PPP geometry for the positively ( $\mathrm{pH} 4)$, uncharged (pH6), and negatively charged ( $\mathrm{pH} 10)$ interfaces.

To verify whether $\mathrm{SCN}^{-}$acts similarly to other electrolyte solutions, we performed steady state vSFG measurements of potassium thiocyanate solutions in the $\mathrm{O}-\mathrm{H}$ stretching region (Figure S9). At positive and neutral surface charge, KSCN appears to increase the amplitude of the strongly $\left(\sim 3200 \mathrm{~cm}^{-1}\right)$ and weakly $(\sim 3400$ $\mathrm{cm}^{-1}$ ) hydrogen bonded species while retaining the spectral shape of neat pH 4 \& $6 \mathrm{H}_{2} \mathrm{O}$, respectively. The vSFG response is enhanced at $10 \mathrm{mM}$, and then is reduced as the concentration is increased. The $\mathrm{KSCN}$ induced $\mathrm{vSFG}$ intensity in the $0.1-2 \mathrm{M}$ range is stronger than neat $\mathrm{H}_{2} \mathrm{O}$ at $\mathrm{pH} 6$ and similar to neat $\mathrm{pH} 4 \mathrm{H}_{2} \mathrm{O}$. At the negatively charged surface $(\mathrm{pH}=10)$ the spectra are attenuated and the spectral density shifts to $3500 \mathrm{~cm}^{-1}$, indicating that the majority of O-H species are weakly hydrogen bonded, similar to what is seen for halide salts. ${ }^{10}$

Classical molecular dynamics simulations yield an adsorption geometry where the thiocyanate ion is parallel to the $\alpha-\mathrm{Al}_{2} \mathrm{O}_{3}(0001) / \mathrm{H}_{2} \mathrm{O}$ surface plane. This adsorption geometry means the $\mathrm{SCN}^{-}$ cannot be probed using vSFG in PPP geometry, and this geometry is not seen in DFT simulations. Since DFT-MD simulations would then be required to investigate the adsorption behavior, which is currently not computationally feasible, we cannot study $\mathrm{SCN}^{-}$adsorption using MD simulations. Thus, we infer from the experimental results that $\mathrm{SCN}^{-}$acts similarly to other monovalently charged halide salts in the interfacial region of positively, neutral, and negatively charged surfaces while providing information regarding the local electrostatic potential. ${ }^{11}$ 


\section{Comparison of Interfacial Water Structuring by KSCN to Halide Ions using vSFG}

A

0.1 M Mono/Divalent Cations vs. Bulk pH

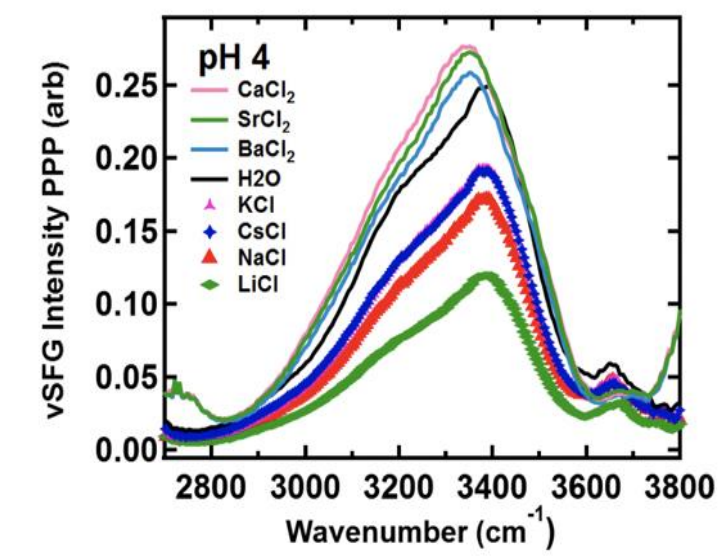

$\mathrm{C}$

0.1 M Mono/Divalent Cations vs. Bulk pH

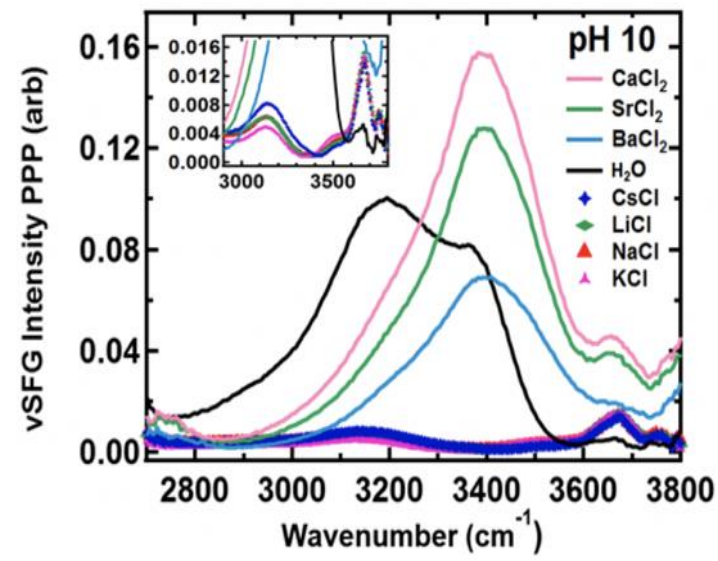

$\mathrm{B}$

\section{$\mathrm{KSCN}$ in $\mathrm{OH}$ Stretching Region}

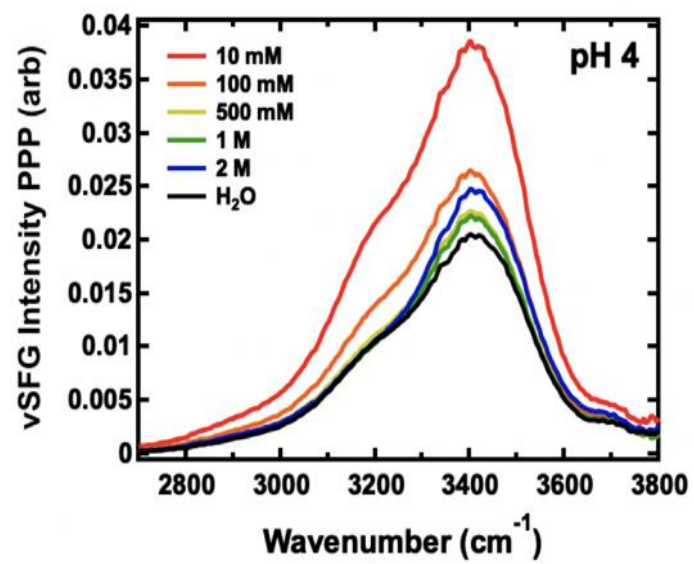

$\mathrm{D}$

$\mathrm{KSCN}$ in $\mathrm{OH}$ Stretching Region

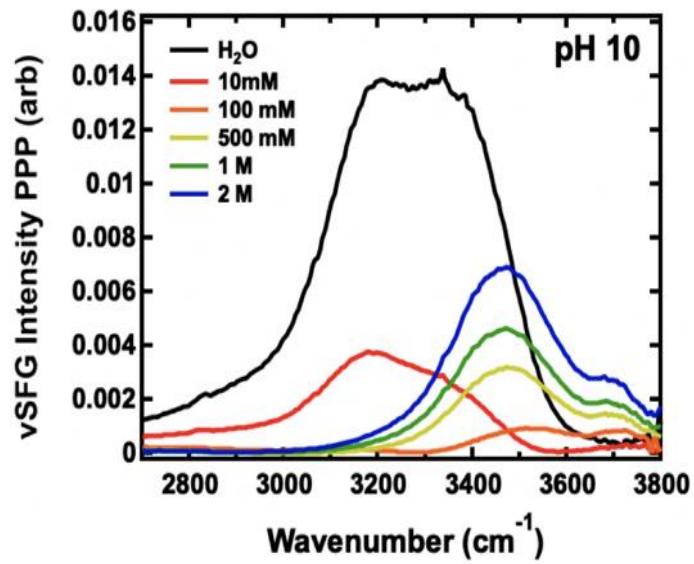

Figure S13: Comparison of previous vSFG data from $0.1 \mathrm{M}$ monovalent and divalent halide cations at bulk $\mathrm{pH} 4$ (A) and $\mathrm{pH} 10$ (C) conditions with vSFG spectra of $\mathrm{KSCN}$ solutions at $\mathrm{pH} 4$ (B) and $\mathrm{pH} 10$ (D) in this work. The $\mathrm{KSCN}$ solutions rearrange interfacial water populations to an intermediate extent between monovalent and divalent cations. Panels $\mathrm{A}$ and $\mathrm{C}$ taken from the following reference. ${ }^{10}$ 


\section{Comparison of Interfacial and Bulk $\mathrm{SCN}^{-}$Vibrational Frequencies}
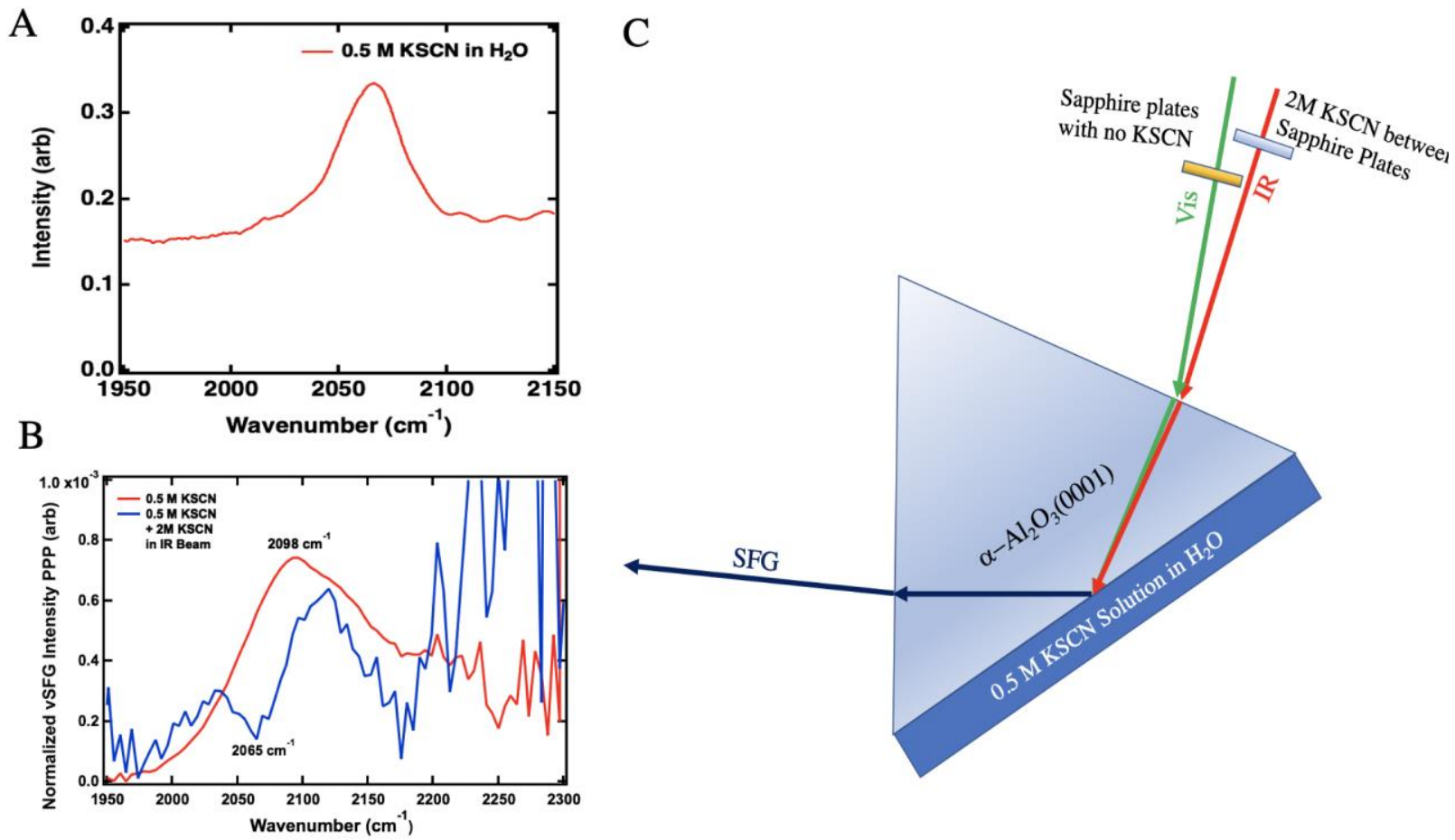

Figure S14: Comparison of A) bulk FTIR spectrum of 0.5 M KSCN solution in bulk $\mathrm{H}_{2} \mathrm{O}$ with the interfacial signature of B) $0.5 \mathrm{KSCN}$ acquired using vSFG at the $\alpha-\mathrm{Al}_{2} \mathrm{O}_{3}(0001) / \mathrm{H}_{2} \mathrm{O}$ interface. The vSFG measurement is compared with B \& C) $2 \mathrm{M} \mathrm{KSCN}$ sandwiched between sapphire plates which depletes the vSFG signal acquired from the interfacial region and the position of the dip agrees with the FTIR vibrational frequency of KSCN.

\section{Coulomb Potential Versus Distance Using a Selection of Dielectric Constants}
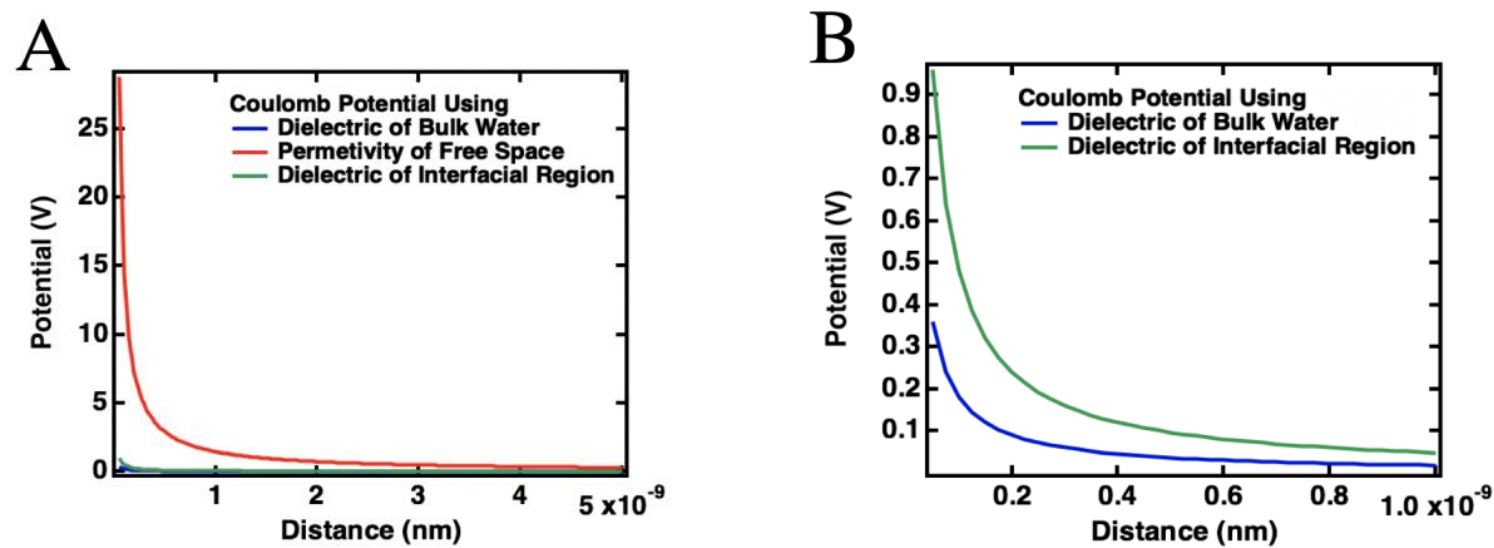

Figure S15: Calculated Coulomb potential versus distance using different values for the dielectric constant of the supporting medium. Panel A) contrasts choosing the dielectric constant as free space $(\varepsilon=1)$, water $(\varepsilon=80)$, or an estimation of the interfacial dielectric constant $(\varepsilon=30),{ }^{12}$ while $\left.\mathbf{B}\right)$ zooms in on only results generated using $\varepsilon_{\text {water }}$ or $\varepsilon_{\text {interface. }}$ 
To approximate the distance at which $\mathrm{SCN}^{-}$ions could sense local charges, the Coulomb potential versus distance was calculated using various values for the dielectric constant of the interfacial region using equation $\mathbf{S 4}$.

$$
V_{E}=\frac{1}{4 \pi \varepsilon_{0} \varepsilon_{\text {media }}} \frac{Q}{r}
$$

\section{Simulated Eigenmodes of KSCN}

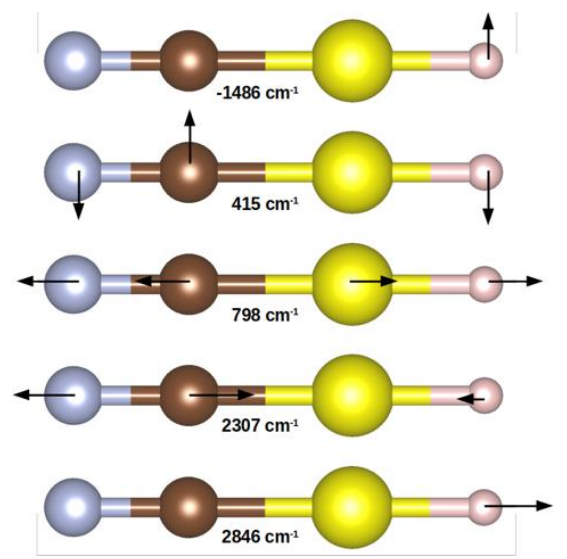

Figure S16: Eigenmodes associated with HSCN generated from DFT-MD simulations.
To better understand the local environment of $\mathrm{KSCN}$ at the $\alpha-\mathrm{Al}_{2} \mathrm{O}_{3}(0001) / \mathrm{H}_{2} \mathrm{O}$ interface we computed the vibrational properties of $\mathrm{KCSN}$. We observe $\mathrm{SCN}^{-}$adsorbing on the surface such that the $\mathrm{S}$ atom coordinates with aluminol groups and the $\mathrm{N}$ atom pointing into solution at an angle of about $45^{\circ}$ (Figure S18 and Figure S19), consistent with similar calculations at the air-water interface. ${ }^{13}$ While $\mathrm{SCN}^{-}$ has a stretching mode at $2185 \mathrm{~cm}^{-1}$, HSCN has modes at $2310 \mathrm{~cm}^{-1}$ and $2846 \mathrm{~cm}^{-1}$, corresponding to $C \equiv N$ and $\mathrm{H}-\mathrm{S}$ stretches, respectively. Thus, the formation of weak $\mathrm{H}-$ bonds with $\mathrm{S}$ can blueshift stretching modes and generate higher frequency modes. At the alumina interface we find the $\mathrm{SCN}^{-}$ion exhibits peaks in the VDOS at 1800 and 2200 $\mathrm{cm}^{-1}$ (Figure S20). Thus, the $2120 \mathrm{~cm}^{-1}$ peak is associated with $\mathrm{SCN}^{-}$adsorbed on the alumina surface, where the formation of H-bonds with surface aluminols creates bands in the 2100-2300 $\mathrm{cm}^{-1}$ range, corresponding to a combination of $\mathrm{S}-\mathrm{H}$ and $C \equiv N$ vibrations.

\section{Simulation of Interfacial KSCN SFG Spectra at the $\alpha-\mathrm{Al}_{2} \mathrm{O}_{3}(0001) / \mathrm{H}_{2} \mathrm{O}$ Interface}

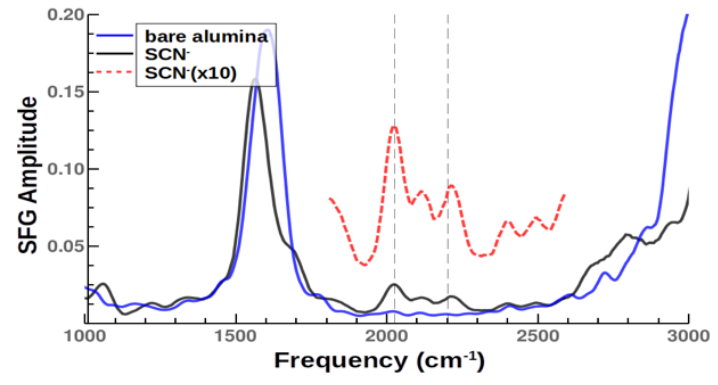

Figure S17: The computed SFG spectrum of both bare alumina and alumina with a single $\mathrm{SCN}^{-}$adsorbed on the surface. The vertical dashed lines indicate peaks at 2050 and $2200 \mathrm{~cm}^{-1}$.

lower amplitude in this range. Note there is no peak at around $1800 \mathrm{~cm}^{-1}$, although the VDOS shows that the $\mathrm{SCN}^{-}$ion has a mode near this frequency (Figure S20). This indicates the $\sim 1800$
We computed the SFG spectrum of a bare $\alpha-\mathrm{Al}_{2} \mathrm{O}_{3}(0001) / \mathrm{H}_{2} \mathrm{O}$ interface and of $\mathrm{SCN}^{-}$ at the $\alpha-\mathrm{Al}_{2} \mathrm{O}_{3}(0001) / \mathrm{H}_{2} \mathrm{O}$ interface (Figure S17). Our results indicate the experiments at $\mathrm{pH}=6$ are likely probing the stretching mode of an aluminol-SCN ${ }^{-}$ complex at the alumina surface, rather than $\mathrm{SCN}^{-}$ions fully solvated by $\mathrm{H}_{2} \mathrm{O}$. The simulation with $\mathrm{SCN}^{-}$exhibits peaks around 2050 and $2200 \mathrm{~cm}^{-1}$, whereas the bare $\alpha-\mathrm{Al}_{2} \mathrm{O}_{3}(0001) / \mathrm{H}_{2} \mathrm{O}$ interface has a much

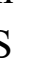

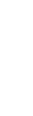


$\mathrm{cm}^{-1}$ peak is either not SFG active or cannot be resolved due to its proximity to the $\mathrm{H}_{2} \mathrm{O}$ bending mode. The presence of multiple peaks within the range of $2000-2200 \mathrm{~cm}^{-1}$ is likely due to the association of $\mathrm{S}$ atoms of $\mathrm{SCN}^{-}$molecules with multiple aluminol sites at the interface (Figure S18 and S19), thereby yielding a small range of stretching modes. Thus, it is likely that the 2120 $\mathrm{cm}^{-1}$ measured in experiments is due to the stretching modes associated with an interfacial Al-O$\mathrm{H}_{-} \mathrm{SCN}^{-}$complex.

\section{Snapshot of Potassium Thiocyanate at the pH $6 \alpha-\mathrm{Al}_{2} \mathrm{O}_{3}(0001) / \mathrm{H}_{2} \mathrm{O}$ Interface}

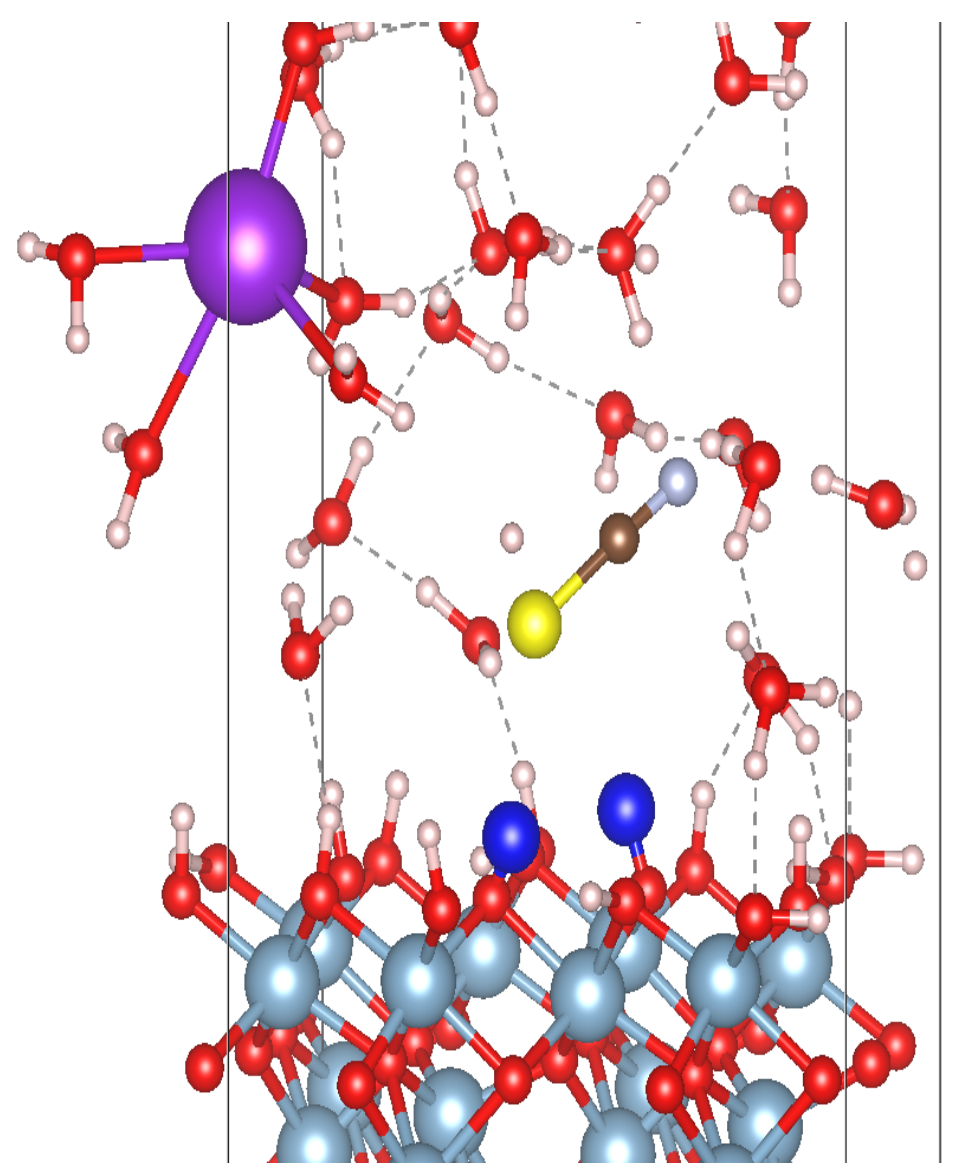

Figure S18: Snapshot of the $\alpha-\mathrm{Al}_{2} \mathrm{O}_{3}(0001) / \mathrm{H}_{2} \mathrm{O}$ interface with $\mathrm{KSCN}$, where the red, white, light-blue, gray-blue, brown, yellow, and purple atoms are $\mathrm{O}, \mathrm{H}, \mathrm{A}, \mathrm{N}, \mathrm{C}, \mathrm{S}$, and $\mathrm{K}$, respectively. The two $\mathrm{H}$-atoms associated with the $\mathrm{S}$ atom of $\mathrm{SCN}^{-}$are highlighted in blue, defined as the $\mathrm{H}$ atoms which are within the first peak in the $\mathrm{S}-\mathrm{H}$ RDF (Figure S5). 
21. S-H Radial Distribution Function for $\mathrm{SCN}^{-}$in Water and at the $\alpha-\mathrm{Al}_{2} \mathrm{O}_{3}(0001) / \mathrm{H}_{2} \mathrm{O}$ Interface

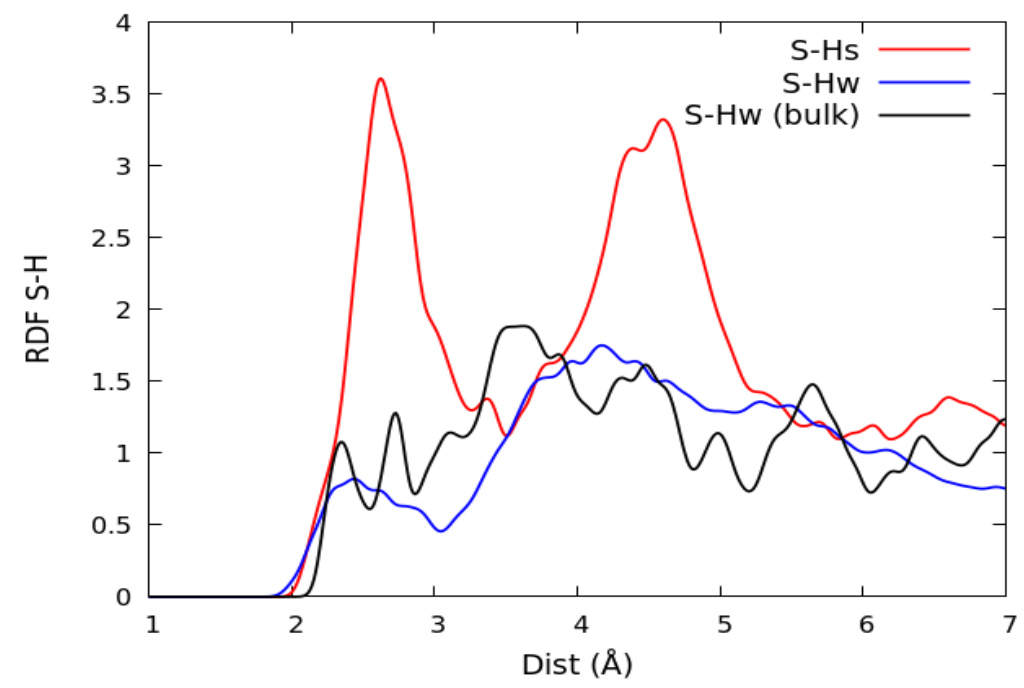

Figure S19: The S-H radial distribution function, where the blue and red lines show the function for KSCN at the $\alpha$ (0001) interface and in bulk water, respectively, and the black line shows the function $\mathrm{KSCN}$ solvated by $128 \mathrm{H}_{2} \mathrm{O}$ molecules.

\section{VDOS of KSCN Species at the $\alpha-\mathrm{Al}_{2} \mathrm{O}_{3}(0001) / \mathrm{H}_{2} \mathrm{O}$ Interface and in Bulk Water}
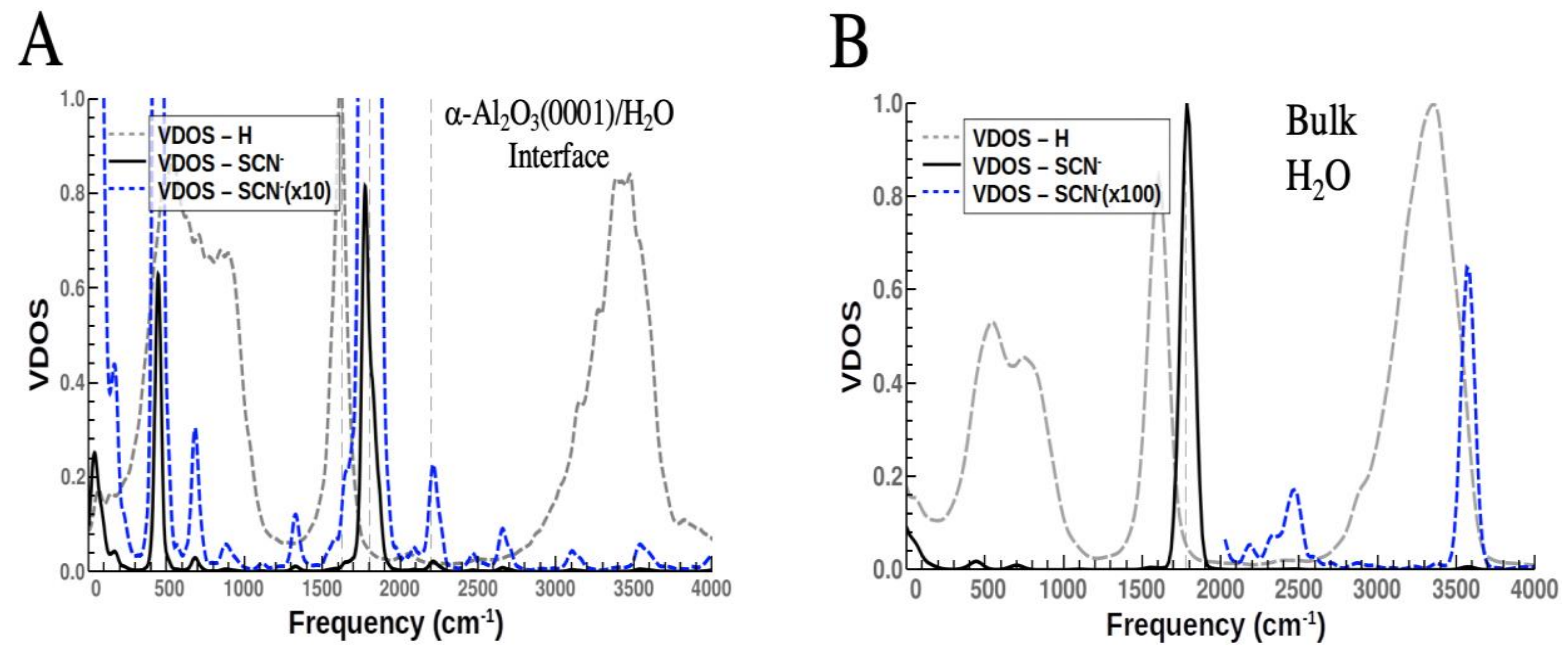

Figure S20: A)The VDOS of $\mathrm{SCN}^{-}$, averaged over all atoms in $\mathrm{SCN}$, at the $\alpha-\mathrm{Al}_{2} \mathrm{O}_{3}(0001) / \mathrm{H}_{2} \mathrm{O}$ interface. The gray dashed line is the VDOS due to $\mathrm{H}$ atoms, the black solid line is due to $\mathrm{SCN}^{-}$, and the blue dashed line is the same multiplied by 100 to show the higher frequency stretching modes. B) Vibrational density of states for KSCN in water (note: $\mathrm{SCN}^{-}$and $\mathrm{K}^{+}$do not form a contact pair in $\mathbf{B}$ ). 


\section{References}

1. Frisch, M. J. T., G. W.; Schlegel, H. B.; Scuseria, G. E.; Robb, M. A.; Cheeseman, J. R.; Scalmani, G.; Barone, V.; Petersson, G. A.; Nakatsuji, H.; Li, X.; Caricato, M.; Marenich, A. V.; Bloino, J.; Janesko, B. G.; Gomperts, R.; Mennucci, B.; Hratchian, H. P.; Ortiz, J. V.; Izmaylov, A. F.; Sonnenberg, J. L.; Williams-Young, D.; Ding, F.; Lipparini, F.; Egidi, F.; Goings, J.; Peng, B.; Petrone, A.; Henderson, T.; Ranasinghe, D.; Zakrzewski, V. G.; Gao, J.; Rega, N.; Zheng, G.; Liang, W.; Hada, M.; Ehara, M.; Toyota, K.; Fukuda, R.; Hasegawa, J.; Ishida, M.; Nakajima, T.; Honda, Y.; Kitao, O.; Nakai, H.; Vreven, T.; Throssell, K.; Montgomery, J. A., Jr.; Peralta, J. E.; Ogliaro, F.; Bearpark, M. J.; Heyd, J. J.; Brothers, E. N.; Kudin, K. N.; Staroverov, V. N.; Keith, T. A.; Kobayashi, R.; Normand, J.; Raghavachari, K.; Rendell, A. P.; Burant, J. C.; Iyengar, S. S.; Tomasi, J.; Cossi, M.; Millam, J. M.; Klene, M.; Adamo, C.; Cammi, R.;

Ochterski, J. W.; Martin, R. L.; Morokuma, K.; Farkas, O.; Foresman, J. B.; Fox, D. J., Gaussian 16, Revision C.01. Gaussian Inc.: Wallingford, CT, 2016.

2. Chai, J.-D.; Head-Gordon, M., Long-Range Corrected Hybrid Density Functionals with Damped Atom-Atom Dispersion Corrections. Phys. Chem. Chem. Phys. 2008, 10 (44), 66156620 .

3. Dunning, T. H., Gaussian-Basis Sets for Use in Correlated Molecular Calculations .1. The Atoms Boron Through Neon And Hydrogen. J. Chem. Phys. 1989, 90 (2), 1007-1023. 4. Nagata, Y.; Mukamel, S., Vibrational Sum-Frequency Generation Spectroscopy at the Water/Lipid Interface: Molecular Dynamics Simulation Study. J. Am. Chem. Soc. 2010, 132 (18), 6434-6442.

5. DelloStritto, M.; Piontek, S. M.; Klein, M. L.; Borguet, E., Relating Interfacial Order to Sum Frequency Generation with Ab Initio Simulations of the Aqueous $\mathrm{Al}_{2} \mathrm{O}_{3}(0001)$ and (1120) Interfaces. J. Phys. Chem. C 2018, 122 (37), 21284-21294.

6. Piontek, S. M.; Tuladhar, A.; Marshall, T.; Borguet, E., Monovalent and Divalent Cations at the $\alpha$-A12O3(0001)/Water Interface: How Cation Identity Affects Interfacial Ordering and Vibrational Dynamics. The J. Phys. Chem. C 2019, 123 (30), 18315-18324.

7. Shen, C.; Buck, M.; Wilton-Ely, J.; Weidner, T.; Zharnikov, M., On the Importance of Purity for the Formation of Self-Assembled Monolayers from Thiocyanates. Langmuir 2008, 24 (13), 6609-6615.

8. $\quad$ Eng, P. J.; Trainor, T. P.; Brown, G. E.; Waychunas, G. A.; Newville, M.; Sutton, S. R.; Rivers, M. L., Structure of the Hydrated a- $\mathrm{Al}_{2} \mathrm{O}_{3}$ (0001) Surface. Science 2000, 288 (5468), 1029-1033.

9. Hass, K. C.; Schneider, W. F.; Curioni, A.; Andreoni, W., First-Principles Molecular Dynamics Simulations of $\mathrm{H}_{2} \mathrm{O}$ on a- $\mathrm{Al}_{2} \mathrm{O}_{3}$ (0001). J. Phys. Chem. B 2000, 104 (23), 5527-5540.

10. Piontek, S. M.; Tuladhar, A.; Marshall, T.; Borguet, E., Monovalent and Divalent Cations at the $\alpha-\mathrm{Al}_{2} \mathrm{O}_{3}(0001) /$ Water Interface: How Cation Identity Affects Interfacial Ordering and Vibrational Dynamics. J. Phys. Chem. C 2019, 123 (30), 18315-18324.

11. Wang, R.; DelloStritto, M.; Remsing, R. C.; Carnevale, V.; Klein, M. L.; Borguet, E., Sodium Halide Adsorption and Water Structure at the $\alpha$-Alumina (0001)/Water Interface. The J. Phys. Chem. C 2019, 123 (25), 15618-15628.

12. Schlaich, A.; Knapp, E. W.; Netz, R. R., Water Dielectric Effects in Planar Confinement. Phys. Rev. Lett. 2016, 117 (4), 048001.

13. Tesei, G.; Aspelin, V.; Lund, M., Specific Cation Effects on $\mathrm{SCN}^{-}$in Bulk Solution and at the Air-Water Interface. J. Phys. Chem. B 2018, 122 (19), 5094-5105. 